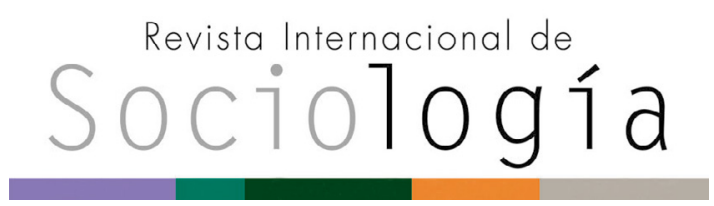

Revista Internacional de Sociología RIS

vol. 79 (2), e184, abril-junio, 2021, ISSN-L:0034-9712 http://doi.org/10.3989/ris.2021.79.2.20.48

\section{LA BUROCRATIZACIÓN NEOLIBERAL DE LA PARTICIPACIÓN CIUDADANA EN ESPAÑA}

\author{
Jone Martínez-Palacios \\ Universidad del País Vasco/ Euskal Herriko \\ Unibertsitatea (UPV/EHU) \\ jone.martinez@ehu.eus \\ ORCID ID: https://orcid.org/0000-0002-9354-3148
}

Cómo citar este artículo / Citation: Martínez-Palacios, J. 2021. "La burocratización neoliberal de la participación ciudadana en España". Revista Internacional de Sociología 79 (2): e184. http://doi.org/10.3989/ ris.2021.79.2.20.48

\begin{abstract}
Resumen
Ante el giro participativo global que se registra en las denominadas democracias occidentales, este artículo tiene por objetivo conocer la forma particular que adopta dicho giro en España. Para ello, se realiza un análisis desde un punto de vista genético de la institucionalización de la participación ciudadana en el país entre los años 1978 y 2017. De dicho análisis se concluye la existencia de una tendencia neoliberal con la que se implementa el giro participativo. En el texto se esbozan los tres movimientos principales que componen el diagnóstico de giro participativo neoliberal: 1) La naturalización de topos de la crisis de la democracia de carácter mecanicista; 2) la burocratización neoliberal de la participación y 3) la mercantilización privativa de la participación. Se explican las líneas generales de los tres movimientos y se profundiza en el análisis particular del segundo de ellos, la burocratización neoliberal de la participación ciudadana.
\end{abstract}

\section{Palabras clave}

Acción pública en participación, giro participativo global, neoliberalismo, democracia participativa, crisis de la democracia, mercantilización de la participación.

\section{THE NEOLIBERAL BUREAUCRATIZATION OF CITIZEN PARTICIPATION IN SPAIN}

Copyright: () 2021 CSIC. Este es un artículo de acceso abierto distribuido bajo los términos de la licencia de uso y distribución Creative Commons Reconocimiento 4.0 Internacional (CC BY 4.0).

Recibido: 30/04/2020. Aceptado: 21/09/2020

Publicado: 22/06/2021

\section{Abstract}

In view of the global participative turn that is registered in the so-called western democracies, this article aims to know the particular form that this turn takes in Spain. To this end, a genetic analysis of the institutionalisation of citizen participation in the country, between 1978 and 2017 , is carried out. From this analysis is concluded the neoliberal trend of the participatory turn that is implemented in Spain. The text describes the three main movements that make up the diagnosis of the neoliberal participatory turn: 1) the naturalization of a topos with a mechanistic nature of the crisis of democracy; 2) the neoliberal bureaucratization of participation, and 3) the privatization of participation. The general lines of the three movements are explained, and the particular analysis of the second of them, the neoliberal bureaucratization of citizen participation, is described.

\section{KEYWORDS}

Public action in participation, global participatory turn, neoliberalism, participatory democracy, crisis of democracy, privatization of participation. 


\section{INTRODUCCIÓN}

Aparentemente, nunca ha sido tan fácil como hoy, en la segunda década del siglo XXI, intervenir en la acción pública vía participación o deliberación. La inflación de productos participativos parece interesada en que la ciudadanía integre sus propuestas e ideas en la definición de los asuntos públicos. Sin embargo, en este texto planteo la posibilidad de que estemos ante una realidad aparente y me inclino a responder afirmativamente, pero, con matices, a la pregunta de Baiocchi y Ganuza (2017: 7): "participation is the buzzword of the neoliberal era".

En este artículo sostengo que España asiste a un giro participativo neoliberal (GPN) desde el año 2010, momento en el que estalla la producción de los textos de ley sobre participación ciudadana y se produce un aumento en el uso del procedimiento de externalización en materia de participación por parte de las administraciones públicas (Martínez-Palacios 2021). Así, el GPN es un diagnóstico que sintetiza una realidad: que los esfuerzos de la mano de obra pública, cuando está mediada por una privada de naturaleza neoempresarial en materia de participación, contrariamente al discurso que anuncian, se orientan a organizar el desinterés y el desconocimiento político de la ciudadanía. Dicho de otro modo, esos esfuerzos se orientan a naturalizar una política de la indiferencia hacia la política pública por medio de la participación ciudadana. Como explico más adelante ( $v$. tercer apartado), a este diagnóstico llego habiendo estudiado la institucionalización de la acción pública en participación en España entre los años 1978 y 2017 desde una perspectiva genética1. Estudiar la acción pública quiere decir, siguiendo los parámetros en los que la concibe la sociología de la acción pública de la escuela francesa, analizar el "espacio sociopolítico construido, tanto por técnicas e instrumentos, como por finalidades, contenidos y proyectos de diferentes actores" (Lascoumes y Le Galès 2005: 12).

Con la entrada de la primera década del siglo XXI, comienza a reflexionarse sobre un fenómeno al que se hace referencia como la 'industria', la 'ingeniería', el 'mercado', la 'empresa' de la participación (Baiocchi y Ganuza 2017; Lee 2015; Nonjon 2005). Estos términos comienzan a emplearse para describir los efectos inesperados de la generalización de las dinámicas de la participación en todos los campos sociales$^{2}$. El campo económico, mediático, administrativo, burocrático, político... todos incorporan un discurso y una dinámica participativa que amplía el área de trabajo de las y los analistas de la democracia participativa. Si hasta el momento los trabajos llevados a cabo en este ámbito se centraban en documentar dispositivos y experiencias o en estudiar las condiciones materiales y políticas de la participación y sus efectos, con la generalización de la práctica partici- pativa entran nuevas problemáticas de trabajo relativas a la profesionalización de la participación (Nonjon 2005), la estandarización de la democratización (Lee 2015), o la introducción de criterios de mercado en la gestión pública de la participación (Baiocchi y Ganuza 2017; Hendriks y Carson 2008), entre otras.

Todas ellas sirven para documentar la emergencia de una industria de la participación, registrar lo que parecen nuevas prácticas participativas e identificar las dinámicas de internacionalización de las mismas. A partir de ahí, los términos 'participatory turn' (Bherer et al. 2017), 'tournat participatif (Mazeaud y Nonjon 2018) o 'partizipative Wende' (Hüller 2010) han servido para agrupar problemáticas relativas a la existencia de una ingeniería de la participación que funciona a nivel global.

De momento, el término compuesto 'giro participativo' tiene un uso restringido al campo académico $y$, si bien su empleo extensivo hace referencia a la generalización de la práctica participativa o paraparticipativa en los distintos ámbitos, su uso más específico remite a los análisis que derivan de la constatación de la existencia de la industria, la ingeniería o, incluso, el mercado de la democracia participativa.

Con todo, el giro participativo global es un fenómeno multiescalar cada vez más documentado en el campo académico (Mazeaud y Nonjon 2018; Bherer et al. 2017; Baiocchi y Ganuza 2017; Ganuza y Fernández 2012) que, lejos de darse en contextos abstractos, se estructura en torno a las lógicas y condiciones de posibilidad históricas, materiales y simbólicas de cada momento. Concretamente, el giro no toma la misma forma en Francia, cuya tradición participativa republicana impregna los productos participativos (Mazeaud y Nonjon 2018), que en España, donde la "democracia de consejos" (Ganuza 2010) conecta con la preferencia deliberativa basada en prácticas clientelares de la cultura política española (Ramió 2016). De ahí que sea necesario documentar ese giro, tanto de forma particular como de manera colectiva, a fin de comprender las dinámicas internas (locales, nacionales, estatales, etc.) y externas (internacionales) y, sobre todo, los cruces entre ellas, que son los que explican sus futuros movimientos.

El trabajo de investigación que presento en el siguiente artículo ha de entenderse en relación con ese objetivo de documentar, analizar y estudiar las consecuencias del giro. Para ello, siendo la institucionalización de la participación uno de los elementos comunes del giro participativo en todos los lugares del mundo, entre 2016 y 2019 he llevado a cabo un estudio de la institucionalización de la acción pública de participación en España entre los años 1978 y 2017. El material analizado durante esos años $(v$. tabla I) me permite concluir, como desarrollo a continuación, que el giro, en España, no se está dando de cualquier modo, sino que tiene un signo neoliberal. 
Soy consciente de que empleo el término 'neoliberal' cuando su carácter explicativo parece estar más politizado y puesto en cuestión que nunca (Slobodian 2018). El neoliberalismo acoge proyectos y escuelas diversas, lo que hace del concepto una categoría, a veces, demasiado abstracta, recurrentemente empleada para denominar la forma en la que opera la acción pública en los sistemas capitalistas en una etapa concreta. Una etapa en la que se busca la "destrucción de las estructuras colectivas solidarias capaces de obstaculizar la lógica de acumulación mercado puro"3 (Bourdieu 1998).

En este artículo, me apoyo en los estudios de la teoría crítica para pensar esta lógica de funcionamiento del capitalismo financiarizado. Desde esta perspectiva, hablar de neoliberalismo implica, necesariamente, remitirse al capitalismo evitando una comprensión teleológica del mismo. Para ello, sobre las tesis marxianas, apoyadas en las lecturas consagradas sobre el tema de Harvey (2014), Hibou (2012), Nancy Fraser y Rachel Jaeggi (2019: 32) o Wendy Brown (2015), me interesa caracterizar el capitalismo "como una secuencia encauzada de regímenes de acumulación que se despliega diacrónicamente en la historia" (Fraser y Jaeggi 2019: 71). Lo característico del capitalismo financiarizado es que su lógica es neoliberal, que "autoriza al capital financiero a que discipline al Estado y al público en interés inmediato de los inversores privados" (Fraser y Jaeggi 2019: 84) y que, además, lo hace ejerciendo el "uso de la fuerza del derecho" para mantener el estado de las cosas (Slovodian 2018). En ese sentido y siguiendo a Brown, el proyecto neoliberal se orienta al desmantelamiento de los procesos de democratización y a la comercialización de la acción pública, instalando en su lugar los mercados y a la moral (Brown 2015: 108), diluyendo, a través de la ley, el peso del habitus en favor del ethos. En lo particular, siguiendo a Hibou, el neoliberalismo se caracteriza por la ampliación de los regímenes jurídicos multiplicando el número de textos normativos, por abrir el proceso de toma de decisiones sobre las normas de la acción pública a agentes empresariales y por esgrimir normas de tipo moral que esbozan las disposiciones de un sujeto que encaja en la "fantasía de la individualidad" (Hibou 2012).

Así, tras el análisis empírico llevado a cabo, en este artículo sostengo que hay tres movimientos que caracterizan el giro participativo neoliberal en España, el cual permite la entrada de la empresa con intereses privados en la toma de decisión del Estado a través de los dispositivos de participación, dando como resultado un empobrecimiento de la democracia. Los tres movimiento son: 1) la naturalización de un topos de la crisis de la democracia que hacen suyo las compañías privadas y utilizan para vender productos participativos para la acción pública a través de fórmulas como la externalización; 2) la burocratización neoliberal de la participación, que canaliza los valores de la nueva gestión pública que, en general, orientan a las empresas privadas, y 3 ) la mercantilización privativa de la participación ciudadana que hace que esta se haya convertido en un producto comercializable orientado a la acumulación de capital en cualquiera de sus formas (cf. económico, social, cultural, simbólico).

El objetivo principal de este texto no es desarrollar de forma pormenorizada la tesis completa del GPN, sino detenerme en el análisis de uno de sus movimientos, que da título al artículo. No obstante, en cuanto que la burocratización de la participación se da en relación con la mercantilización y con la construcción de un topos de la crisis de la democracia mecanicista, considero importante presentar una cartografía à minima que relacione los tres movimientos.

Por eso, este artículo se divide en cinco apartados. Tras este marco introductorio, en el segundo apartado metodológico explico en qué consiste el enfoque genético con el que abordo el análisis y expongo el material empírico en el que me baso para llegar a la identificación de los tres movimientos relacionados más arriba. Aquí detallo aquellos que me han permitido, específicamente, introducir el movimiento en cuyo análisis me centro en el cuarto apartado del texto: la burocratización neoliberal.

En el tercer apartado ofrezco una caracterización global del diagnóstico del GPN. Introduzco brevemente los movimientos primero y tercero para, más adelante, comprender la interrelación en la que aparecen con la práctica de la burocratización de la participación ciudadana.

En el cuarto apartado, por la vigencia del debate sobre la burocratización de la vida pública y política (Hibou 2012), el incremento de trabajos sobre la relación entre burocracia y participación (Mazead y Nonjon 2018) y porque nos encontramos en un contexto en el que casi todas las Comunidades Autónomas de España trazan sus planes de leyes sobre participación y transparencia ( $v$. anexo I), estudio las posibilidades y peligros que tiene la burocratización de la acción pública de la participación.

En el último apartado, retomo las principales ideas del trabajo y ofrezco una serie de puntos sobre los que seguir indagando.

\section{ESTUDIAR LA INSTITUCIONALIZACIÓN DE LA PARTICIPACIÓN CIUDADANA EN ESPAÑA (1978- 2017). METODOLOGÍA Y MATERIAL EMPÍRICO}

Con el fin de conocer el sentido del giro participativo en España, estudio la institucionalización de la participación en el país entre 1978 y 2017 . Es decir, la forma en la que las administraciones públicas incorporan el imperativo participativo. Para ello, anali- 
zo la acción pública en materia de participación desde un enfoque estructuralista genético, inspirado en la obra de Pierre Bourdieu.

El pensamiento genético para el estudio de la acción pública en materia de participación indaga en la producción de las relaciones de poder entre agentes a través del estudio de las lógicas de campo. Desde esta perspectiva, se busca identificar los principios de visión y división del mundo que hoy nos aparecen dóxicos. Esto lleva a analizar, con un enfoque sociohistórico, la posición social de los agentes productores de servicios de la participación y la emergencia de los contenidos y naturaleza de los productos de participación ciudadana que se ofrecen en el campo político.

De este modo, indago en la génesis de lo que aparece naturalizado (productos participativos de la tabla 1), estudiando su proceso de producción. Identificando, en primer lugar, la posición de los agentes productores de discursos, documentos de ley y dispositivos de participación; analizando la relación de estos agentes en el campo de poder global (indagando en su relación con el campo político, campo económico, etc.), y estudiando las interacciones y relaciones de poder entre estos durante el proceso de producción.

Este enfoque genético se convierte en una postura epistemológica en cuanto que asume que, para conocer lo que hoy acontece, es necesario mirar no solo la composición de un campo (el participativo), sino atender al movimiento que existe en el proceso de constitución del mismo. Aunque no pueda mostrarse el detalle del análisis en este texto, se trata de interrogar a cada producto constitutivo del campo de la participación institucional, sistemáticamente, con la ayuda de protocolos de recogida de datos ( $v$. anexo III para fichas de sistematización de guías, manuales sobre los que se centra la conclusión de la burocratización de la participación), por los agentes que lo producen, su posición en relación con el campo global, su estructura interna y externa y sus relaciones con otros productos del campo.

Ya he mencionado que el giro participativo se caracteriza por la inflación de productos participativos. Ante la imposibilidad de estudiarlos todos, en este trabajo opto por seleccionar los principales instrumentos políticos orientados a crear y a mantener instituciones según los criterios que esgrimen Lawrence y Suddaby (2006) en sus estudios sobre el trabajo institucional. Así me detengo en: leyes, discursos de Estado, documentos orientados a la asesoría, teorización, rutinización, promoción y definición de categorías y productos que permiten un mimetismo institucional. Se trata de una muestra diversa que recoge los hitos discursivos, jurídicos y de las prácticas de la implementación de la acción pública en participación. Para llegar a ella, se han realizado consultas a expertos en materia de implementación de políti- cas de participación (agentes académicos, técnicos de participación y consultorías), revisado los documentos que constituyen lo que puede denominarse el régimen jurídico de la participación en España y seguido las ofertas de las principales agencias que dan servicios de participación en el país.

Tabla 1.

Resumen del material empírico analizado

Productos participativos relativos al discurso sobre participación

(lo que se dice sobre la participación)

129 discursos sobre PC de la Cámara Baja de las Cortes Generales entre 1978-2017

14 discursos de investidura, de toma de la Presidencia de Gobierno, pronunciados entre 1978-2017

Productos participativos relativos a la regulación, normalización

y estandarización de la participación

(lo que se regula sobre la participación)

76 textos jurídicos sobre participación

72 guías y manuales sobre participación editados y elaborados por instituciones españolas, en los que se indica cómo llevar a cabo un proceso participativo

Productos participativos efectivamente implementados (lo que se lleva a cabo sobre la participación)

67 programas de formación propuestos bajo el paraguas de alguna de las 19 federaciones de municipios españolas

12 convocatorias de empleo público para la figura de ATP 9 monografías de puestos de trabajo de ATP de municipios referentes en políticas participativas

Página web, carta de servicios y memoria de 96 consultorías y grupos de investigación españolas en materia de $\mathrm{PC}$ que ofrecen servicios en la materia a instituciones públicas

8 programas de másteres académicos de participación del Estado español

22 programas de congresos en ciencia política y sociología desarrollados en España. Disciplinas que acogen el grueso de la actividad intelectual en participación en el campo académico

Fuente: Elaboración propia. ATP: Agente técnico de participación. PC: Participación ciudadana.

En resumen, con el enfoque genético "hago hablar" a estos productos, de forma sistematizada, sobre los principios de visión y división que los organizan. Para la sistematización manual del material, se ha procedido a su lectura, extracción de datos significativos según las plantillas de codificación diseñadas para cada parte de la investigación y análisis e interpretación de datos (Martínez-Palacios, 2021: anexos metodológicos).

El diagnóstico del GPN, que introduzco en el siguiente apartado proviene del estudio del conjunto de productos públicos de la tabla 1. No obstante, la identificación del primer movimiento ha sido posible gracias al análisis de los productos vinculados al discurso de la participación. La identificación del segundo movimiento ( $v$. cuarto apartado), ha sido posible gracias al estudio de textos jurídicos, guías y manuales sobre participación ciudadana ( $v$. ane- 
xos I y II para el detalle de material estudiado). Por último, ha sido posible identificar la mercantilización privativa de la participación gracias a los productos efectivamente implementados en procedimientos participativos.

\section{EL GIRO PARTICIPATIVO NEOLIBERAL}

En España, el giro participativo es neoliberal porque está compuesto, al menos, por tres movimientos. El primer movimiento del giro neoliberal tiene que ver con la producción y naturalización del topos de la crisis de la democracia, que introduce una visión sistémica del mundo en la que la participación se presenta, y se concibe, como una solución al estilo médico (participación como terapia). Este primer movimiento consiste en el uso del discurso de la crisis de la democracia como "lugar común, con el que se discute, pero, sobre el que no se discute", como topos (Bourdieu y Wacquant 1998: 109), de una forma que permite ampliar el suelo de ventas al ámbito de la participación de algunas empresas privadas, y naturalizar una forma medicalizada de participación al estilo en el que Ivan Illich concebía la "némesis y la yatrogénesis médica" (1975).

Así, por un lado, el topos de la crisis que se instala en el campo político y económico permite que vendan sus productos los agentes económicos y empresariales que hasta ahora no se interesaban en la democracia participativa ( $v . g$., empresas privadas dedicadas a la telefonía o consultorías no especializadas en materia participativa). Siguiendo las perspectivas sobre el neoliberalismo arriba introducidas, se aprecia la entrada de las corporaciones económicas en la definición de la democratización, implicando el desmantelamiento de una visión democrática ajena a los intereses económicos privados (Brown 2015).

Por otro lado, además de que el terreno de la crisis de la democracia dé entrada a agentes empresariales, también se naturaliza una secuencia circular sobre la puesta en marcha de la democratización que favorece una medicalización de la participación. La secuencia comienza por una idea de crisis para la que es necesario activar la participación. No se discute ni el contenido, ni el origen de dicha crisis, solo se habla de la existencia de una crisis de democracia, de eficiencia democrática, de confianza ciudadana, etc. para la que es necesario tomar medidas participativas, todo ello sin poner en riesgo el sistema representativo y la labor de los partidos políticos. Quienes proponen participación (partidos políticos y empresas) lo hacen poniendo el límite en garantizar el mantenimiento de su propia existencia, dando lugar a un "sesgo participativo" (Navarro 1999).

Esa noción sistémica de crisis hace desplegar una oferta participativa institucional que se traduce en una dispersión de dispositivos deliberativos y participativos, poco relacionados entre sí, pero que generan una apariencia de posibilidad (en la intervención de la decisión). Para dar coherencia a esa dispersión, los dispositivos se presentan bajo la imagen de un sistema (de participación institucional) o un régimen común (de participación institucional) del que se tienen pruebas documentales en discursos y documentos jurídicos desde la primera década del siglo XXI (Martínez-Palacios, 2021). Así, progresivamente, se van introduciendo textos jurídicos que proporcionan el marco normativo para el desarrollo de lo que, a partir del 2010, se denominará "sistema participativo institucional" y a lo que la Ley $8 / 2015$, de 25 de marzo, de Transparencia de la Actividad Pública y Participación Ciudadana de Aragón se referirá como "régimen de la participación ciudadana". Ambas ideas (sistema y régimen) son funcionales a una visión sistémica del mundo que enlaza con el topos mecanicista de la crisis de la democracia. Asimismo, ambas toman cuerpo en los productos jurídicos de la participación, que permiten, como veíamos más arriba, el mantenimiento de un estado de las cosas ventajoso a los agentes con una acumulación de capital global (Fraser y Jaeggi 2019; Slovodian 2018; Brown 2015).

El segundo movimiento, que desarrollo más adelante, tiene que ver con la burocratización neoliberal de la participación, imprescindible para comprender la organización del desinterés que hace neoliberal al giro. Considerando que, en España, gran parte de la acción pública en participación se ha canalizado a través de proyectos normativos (leyes, reglamentos, etc.) (Ganuza 2010; Navarro 1999), explico que en estos documentos se encuentran las pistas de siete prácticas concretas de una nueva racionalización burocrática, que implican tanto la profundización de la tendencia a la estandarización de una forma unívoca de concebir la participación en nombre de la modernización como la normalización de dispositivos morales y disposicionales que facilitan la ampliación de las normas burocráticas y la entrada de la burocracia en la esfera de lo íntimo, ambas cuestiones características de una lógica neoliberal de la gestión de lo público (Hibou 2012). Siguiendo a Brown (2015: 151), el entramado jurídico se convierte en médium para diseminar la racionalidad neoliberal aplicada por empresas privadas.

El tercer movimiento que hace que el giro participativo en España tenga un carácter neoliberal tiene que ver con la mercantilización y progresiva privatización de la acción pública de la participación que viene dado, en parte, por la voluntad de desburocratización administrativa y la entrada de la nueva gestión pública, que se traduce en un nuevo entramado jurídico con un fuerte contenido moralizante (Brown 2015). Sobre esta cuestión existe ya una literatura centrada en la public engagement industry que se instala a nivel global en el año 2000 (Lee 2015). En 
España, ante el discurso de la crisis de la democracia y la burocracia (ante la que se argumenta la necesidad de la participación ciudadana), en la oferta participativa institucional se perciben, a partir de la primera década del siglo XXI, una gestión acumulativa y orientada al beneficio político y económico, y un incremento de dispositivos a favor de la competitividad. En este momento, se puede hablar de la configuración de un "mercado social de la participación" y un "mercado neoliberal de la participación" (Martínez-Palacios 2021). El primero orientado por los principios del comercio justo, el segundo basado en la idea de que la participación puede y debe venderse como un bien a partir del que enriquecerse. Así, este movimiento se caracteriza por registrar el paso de la artesanía de la participación a la industria de la participación ciudadana.

\section{LA BUROCRATIZACIÓN DE LA PARTICIPACIÓN CIUDADANA}

Actualmente, no se pone en cuestión la tesis de una reburocratización global de la acción publica (Bezes 2020). Algunas y algunos autores establecen una relación directa entre la burocratización y las estrategias de modernización administrativa a través de la nueva gestión pública (Clarke y Newman 1997), en las que las políticas de participación ciudadana cobran especial relevancia (Baiocchi y Ganuza 2017; Hibou 2012). Así, "la burocratización al cuadrado" estaría vinculada, según quienes se sitúan en la teoría crítica, a una mayor presencia de las herramientas neoempresariales de gestión, relacionando la lógica neoliberal con la burocrática (Hibou 2012).

Asimismo, ya hay aportaciones en el ámbito de estudio de la participación que indican que esta está orientada a ahondar en los problemas de la burocratización excesiva que dice remediar, y que canaliza una moral de corte neoliberal (Baiochi y Ganuza 2017). Sin embargo, faltan estudios empíricos de los contextos afectados por el giro participativo en los que se detallen las lógicas particulares que toma la burocratización. A esta cuestión está dedicado este apartado.

En primer lugar, cabe decir que con la institucionalización del topos de la crisis de la democracia tiene cabida una crítica a la burocracia generalizada en el campo político y empresarial. Los textos de ley y las guías de participación estudiados dan cuenta de ello en sus preámbulos, tal y como ilustro en las tablas 2 y 3 . Paradójicamente, la participación que se propone para desburocratizar las relaciones entre la ciudadanía y los agentes políticos nace mediada, también, por la burocracia, pero esta se da en el sentido neoliberal aludido anteriormente, que consiste en refinar la naturalización de la misma, expandir sus efectos más allá de la esfera pública e incrementar el poder del derecho (Slobodian 2018; Baiocchi y Ganuza 2017; Hibou 2012).

La noción de burocratización fue empleada por Weber para referirse a la progresiva implementación de los principios de racionalidad legal de las estructuras burocráticas, tal y como él las explicaba. De modo que la noción tiene que ver con alcanzar el ideal normativo esbozado. 'Burocratización' no es exceso en su pensamiento, ni esconde la carga negativa que cien años de burocracia moderna le han dado. Hoy, burocratización hace referencia a las consecuencias inesperadas de los aspectos que la crítica de la burocracia subraya (Hibou, 2012: 21; Young, 2000:132).

Tabla 2.

Referencias recogidas en las leyes de participación ciudadana a los problemas que genera el exceso de burocracia

\begin{tabular}{|c|}
\hline Ley $4 / 2011$, de 31 de marzo, de la buena administración y del buen gobierno de las Illes Balears \\
\hline $\begin{array}{l}\text { La realidad de grandes cambios competenciales entre los diferentes niveles de gobierno, la débil implantación del model gerencial } \\
\text { conseguida en muchos ámbitos institucionales hipotecados por poderosas inercias estructurales, como también la fuerte crisis } \\
\text { económica y de valores sufrida en los últimos meses y con raíces en los últimos años, obligan a subrayar acciones y principios } \\
\text { hoy todavía válidos y a apuntar otros nuevos para afrontar con éxito un cambio definitivo, que permita pasar del modelo netamente } \\
\text { burocrático originario a otro gerencial y de gobernanza, en nuestra administración y nuestra acción de gobierno. }\end{array}$ \\
\hline Ley 4/2006. de 30 de junio, de transparencia y de buenas prácticas en la Administración pública gallega \\
\hline $\begin{array}{l}\text { En el momento actual, es necesario reforzar e impulsar el proceso de racionalización y transparencia en la actividad de la } \\
\text { Administración, con la finalidad de eliminar su imagen de opacidad e inaccesibilidad, que genera desconfianza en la ciudadanía. }\end{array}$ \\
\hline Ley 8/2015, de 25 de marzo, de Transparencia de la Actividad Pública y Participación Ciudadana de Aragón \\
\hline $\begin{array}{l}\text { En un contexto de cambio permanente y profundo, en las últimas décadas el modelo de Gobierno y Administración pública está } \\
\text { siendo objeto de transformaciones estructurales encaminadas a impulsar conceptos innovadores como el gobierno abierto. El } \\
\text { tránsito hacia una Administración relacional, reforzando su legitimidad y eficacia con la apertura al ciudadano, es una respuesta a las } \\
\text { actuales demandas de modelos colaborativos basados en más transparencia y más participación ciudadana en los asuntos públicos. } \\
\text { El Gobierno y la Administración pública deben promover el interés general integrando de forma más efectiva a la sociedad civil, como } \\
\text { fortalecimiento de la democracia representativa. }\end{array}$ \\
\hline
\end{tabular}

Fuente: Elaboración propia 
En primer lugar, la burocratización se refiere a la profundización de la separación del trabajo de su sentido, orientado a una lógica de acumulación, basado en prácticas de replicabilidad y rutinización de las tareas que, al límite, garantizan un aislamiento de ciertos individuos al tiempo que una hiperconectividad de quienes tienen una posición de privilegio (Hibou, 2012).

En segundo lugar, alude al incremento de la racionalización basada en una demanda de obediencia con base en el derecho en el que la orden es impersonal, los deberes y servicios están objetivamente limitados y regidos por un principio de jerarquía administrativa.

En tercer lugar, evoca la existencia de una percepción de la norma burocrática según la cual esta es neutra y objetiva, unívoca y universal. No se pone en cuestión porque no procede, se trata del imperativo jurídico. Así, la burocratización implica "que las actividades de la vida que antes estaban sujetas a normas de tradición, a la acción espontánea o a la decisión colectiva, se convierten en mercancías, o caen bajo el control de las instituciones del Estado, pasando a ser actividades normalizadas, universalizadas y estandarizadas" (Young 2000: 137). Además, esas normas vehiculan disposiciones morales que moldean las prácticas cotidianas según los criterios de competitividad y eficiencia, y dibujan el sujeto neoliberal al que la literatura foucaultina se refiere como empresario de sí mismo (Brown 2015; Hibou 2012).

Vinculado a lo anterior, en cuarto lugar, burocratizar implica hoy la acentuación de la división del trabajo que provee la especialización y la formación técnica racional en la que se basa, la evaluación imparcial que demanda, el incremento del cálculo orientado a la racionalización que la organiza y el apego al registro escrito por lo que se ejecuta, empleando para ello canales virtuales y basados en la abstracción (Hibou, 2012).

De modo que, si las tendencias de burocratización tienen que ver con las estrategias generales descritas, cabe preguntarse, primero, si estas afectan a la acción pública en participación y, segundo, de qué modo lo hacen. La literatura más reciente sobre participación y burocracia responde afirmativamente a la primera pregunta: no hay nada que escape al funcionamiento burocrático en la acción pública de Estados con estructuras burocráticas (Martínez-Palacios, 2021; Mazeaud y Nonjon, 2018; Baiocchi y Ganuza, 2017; Tholen, 2015). Así, ahora resta identificar las prácticas de racionalización burocrática concretas que se dan en cada contexto y ver el sentido de su naturaleza. En lo que sigue, explico siete prácticas detectadas tras el estudio de los productos con carácter prescriptivo de la muestra antes relacionada (textos de ley, guías y manuales sobre la implementación de procesos de participación ciudadana) que me conducen a matizar que la burocratización tiene un signo neoliberal en su implementación ( $v$. tabla 3 , anexos I y II).

\section{PROFUNDIZACIÓN DE LA TENDENCIA A LA ESTANDARIZACIÓN DE UNA FORMA UNÍVOCA DE CONCEBIR LA PARTICIPACIÓN CIUDADANA}

Aunque la estandarización y el modelaje son inherentes a la práctica burocrática, en las burocracias modernas la estandarización no constituía un objetivo en sí mismo, tal y como ocurre en el sentido neoliberal

Tabla 3.

Referencias recogidas en los manuales de participación de las federaciones de municipios a los problemas que genera el exceso de burocracia

\begin{tabular}{l} 
Texto: Participando, creando e innovando. Federación Andaluza de Municipios y Provincias (FAMP). 2005: 18 \\
\hline El refuerzo de la innovación y la creatividad en las Administraciones públicas y, por ende, en las Locales se puede lograr. \\
Orientándose a ofrecer servicios a la ciudadanía más rápidos y de mejor calidad. Reconvirtiendo su forma de trabajar acercándose \\
a la población utilizando las nuevas tecnologías, a través de páginas webs que permitan el acceso a la resolución pronta de \\
problemas, reduciendo la burocracia y comunicando directamente a través de foros, redes, chats, etc. Permitiendo la participación \\
ciudadana en los asuntos públicos a través de los Círculos de Innovación. \\
\hline $\begin{array}{l}\text { Guía Práctica para la Implementación de la Participación Ciudadana en los Gobiernos Locales de Andalucía: estrategias } \\
\text { para la acción. FAMP. } 2012: 13\end{array}$ \\
Esta crisis de legitimidad que padecen actualmente nuestros sistemas democráticos, supone para los municipios abordar nuevos \\
retos que favorezcan el tránsito de los tradicionales modelos de Gobierno Burocráticos hacia nuevos modelos de Gobernanza \\
Democrática en los que el gobierno y las administraciones públicas ocupan un papel de liderazgo y mediación entre los diversos \\
actores sociales. \\
Decálogo de participación ciudadana de Alcobendas, en Guía de instrumentos de participación ciudadana. Federación \\
Española de Municipios y Provincias, 2015: 141 \\
\hline 1) Ser accesible, plural, representativa, activa y abierta, facilitando la igualdad de oportunidades e integración de todos los sectores \\
de la población. 2) Ser sencillas, clara y ágil en la tramitación y desarrollo del proceso, eliminando, en la medida de los posible, la \\
burocracia. (...).
\end{tabular}

Fuente: Elaboración propia 
de la burocratización que señalo aquí. Siguiendo los planteamientos sobre el neoliberalismo indicados más arriba (Slobodian 2018; Brown 2015; Hibou 2012), la estandarización se concibe con el objetivo de mantener un estado de las cosas homogéneo y ampliar la rentabilidad de los productos de participación diseñados para ser reciclados. Ese modelaje es evidente a escala global, hay quien indica que, actualmente, los instrumentos participativos viajan a través del mundo como procesos de fast policy transfer (Baiocchi y Ganuza 2017: 5).

En España, esta dinámica se percibe en los textos jurídicos con más claridad a partir de 2010, con la implantación del dispositivo denominado "proceso de deliberación participativa" (art.9 de la Norma Foral 1/2010, Diputación Foral de Gipuzkoa -DFG-).

Este mecanismo viaja de un texto a otro en gestos de mímesis administrativa, estandarizando la acción pública en participación (cf. art. 33.2.d de la Ley $12 / 2014$, de 16 de diciembre, de Transparencia y Participación Ciudadana de la Comunidad Autónoma de la Región de Murcia; art. 54.4 de la Ley 8/2015 de Transparencia y Participación Ciudadana de Aragón, entre otras). Este mecanismo, producido por dos juristas de la academia vasca, introduce un debate dirigido a consultar con enfoque stakeholder, pensado para su realización al inicio de la política pública y no en la identificación de la necesidad de la misma, puesto que el tema viene dado por la propia Administración Pública.

El modelaje, pretendidamente objetivo, también se aprecia en los manuales producidos por las federaciones de municipios que proponen modelos propios de implementación rápida y prescriptiva de procesos de participación. Estos modelos (cf. imágenes 1, 2 y 3 ) se presentan sin mención de sus condiciones de producción (quién, cómo, cuándo lo ha producido) y conviven a la vez que compiten entre sí.

\section{Imagen 1.}

Modelo 8+ 3 EUDEL

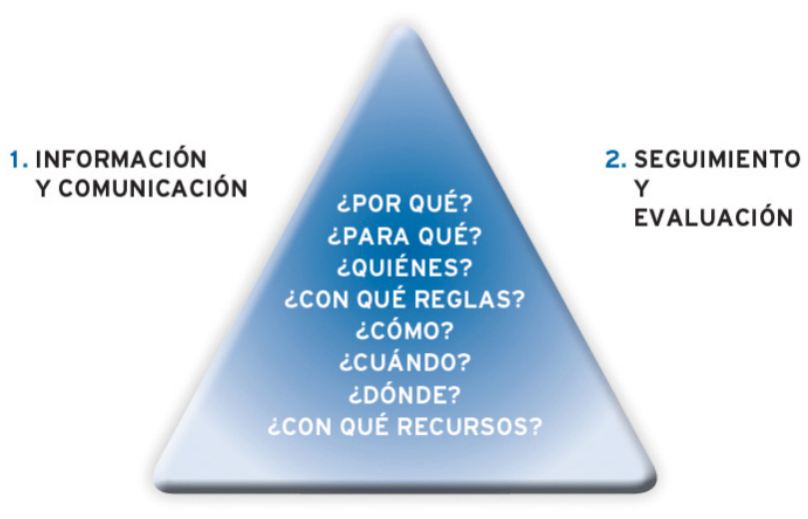

3. COMPROMISOS
Imagen 2.

Ecuación del modelo 3E+2K = Innovación Pública del Ayuntamiento de Tolosa

RREALA

RRAZA

onfidantza

RAGINKORRA

onpromisoa

\section{$3 \mathrm{E}+2 \mathrm{~K}=$ Berrikuntza publikoa}

Fuente: presentación empleada por la alcaldesa en las jornadas de Tabakalera. https://prezi.com/view/IDD6LUVYDhk2O3b2fyH0/ (último acceso: 8 de abril de 2020m).

Imagen 3.

Modelo Geroé de cocreación política (Ley de transparencia de Canarias)
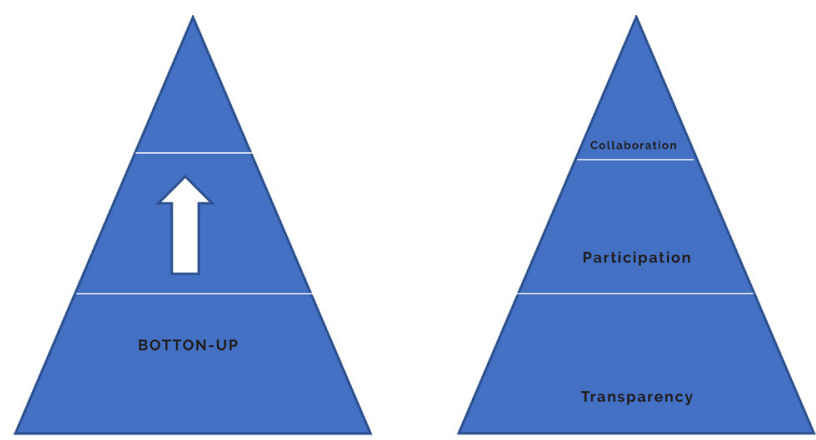

Fuente: FEMP 2015: 95

Es importante señalar que cada uno de los instrumentos que se describen en las imágenes y en los textos de ley, lleva inscrita una visión sobre la participación acerca de la que no se discute, pero que, de hecho, se integra cada vez que se ponen en marcha los procesos de participación deliberativa bajo los parámetros en los que se prescriben. Los dispositivos llevan integrada una visión del mundo y una moral que conectan con la idea de biopolítica que ha sido defendida por Brown (2015) en el momento de caracterizar el giro neoliberal de la acción pública. El ejemplo paradigmático de esta estandarización lo encontramos en dispositivos del tipo $\mathrm{De}$ liberative Polling $\circledast$, que ofrece un modelo estándar de deliberación de marca registrada. La encuesta deliberativa parte del axioma de que una población más informada es capaz de tomar mejores decisiones. Asimismo, el dispositivo integra una idea según la cual es posible que exista un diálogo efectivo y equilibrado alejado de las lógicas de poder, abstraído de un habitus participativo y capaz de construir un ethos participado. Cuando se estandariza un instrumento, no solo se hace un ejercicio de mímesis 
práctica, sino que se vehiculan valores prácticos de distinta naturaleza. Los valores identificados en los ejercicios de mímesis descritos tienen que ver con la máxima liberal de eficiencia y libertad individual. Dibujan una ciudadanía entrenada en el lenguaje de la acción pública y libre de intervenir en el espacio público, sin mención a las prácticas de dominación que puede experimentar ni a los límites que existen en su participación.

\section{PROFUNDIZACIÓN DE LAS FÓRMULAS DE CANALIZACIÓN DE LA PARTICIPACIÓN ORIENTADAS AL CONTROL DE RESULTADOS}

Todo Estado busca mantener el monopolio de las distintas formas de capital de modo que le permita orientar la acción pública. Las lógicas de cálculo son inherentes a la acción estatal. Sin embargo, en una dinámica neoliberal el cálculo se orienta a mantener el estado de las cosas y permitir el acceso de agentes de mercado con los que se busca establecer relaciones para mantener el poder (Slobodian 2018).

En materia de participación, a partir del material estudiado, puedo decir que desde 2010 existe una profundización de la lógica del cálculo y la previsión orientada al control de resultados a través de una serie de herramientas participativas. A partir de ese momento, los textos ya presentan la participación como cauce de legitimación (cf. art. 33.1 de la Ley de transparencia de la Región de Murcia).

No es novedoso decir que, en términos operativos, el encauzamiento de la participación se hace a través de una serie de medidas integradas en el diseño administrativo; hay quien plantea esta cuestión como un elemento central del proyecto neoliberal (Harvey 2014). Medidas como el uso de la división territorial del "distrito" en vez del "barrio" para ordenar y orientar la participación (a través de los Consejos de Distrito). Sin embargo, además de constatar que se utilizan las medidas de división territorial para encauzar y controlar la participación, se percibe que el aumento de la tendencia al cálculo y al control de resultados vía participación se profundiza en la primera década del siglo XXI con herramientas como: la creación de un registro de entidades para la participación en el que se tienen que inscribir aquellas personas que quieren participar; la redacción de un plan anual de participación, que aumenta la capacidad de control institucional sobre su oferta participativa, siendo difícil plantear propuestas participativas ajenas a ese plan durante el curso; la creación de "órganos filtro" como la Comisión Foral para la participación en el caso de la Norma Foral de la Diputación Foral de Guipúzcoa 1/2010; la exportación del procedimiento administrativo común en la gestión participativa, y el refinamiento del enfoque stakeholder. Estas herramientas, además, fortalecen el papel del derecho en la gestión de la participación, dando lugar a una procedimentalización jurídica la participación, una burocracia al cuadrado.

\section{PROCEDIMENTALIZACIÓN JURÍDICA DE LA PARTICIPACIÓN}

Con esta práctica racionalizadora me refiero a la exportación del procedimiento administrativo común en la puesta en marcha de la participación a través del requerimiento de documentos jurídicos como los preacuerdos, acuerdos, modelización de actas de acuerdos, elaboración de informes técnicos previos de autorización, etc.

Esta procedimentalización en términos jurídicos supone poner en valor el capital jurídico y, por ende, a quienes lo poseen, al tiempo que permite aumentar la sensación de control del contexto por parte de los agentes políticos. En esta práctica puede observarse la relación que se establece entre el fortalecimiento de los agentes que disponen de capital jurídico y el neoliberalismo (Slobodian 2018). Este ahínco en el procedimiento administrativo lleva de suyo el uso característico del lenguaje del derecho. El articulado y las explicaciones farragosas sobre cómo poner en marcha un procedimiento de participación ciudadana introducen definiciones incomprensibles que hacen de barrera de entrada a la acción participativa y permiten mantener las cotas de poder de quienes sostienen posiciones dominantes en el campo político porque acumulan un capital jurídico suficiente. Los artículos seleccionados en la tabla 4 muestran la forma práctica que toman las ideas que expongo.

\section{INTEGRACIÓN Y NATURALIZACIÓN DE FÓRMULAS DE ABSTRACCIÓN Y OBJETIVACIÓN DE LA PARTICIPACIÓN CIUDADANA}

En esta cuarta práctica interesa la abstracción a la que ya nos remite el modelaje al que me he referido más arriba, porque incita a la "producción burocrática de la indiferencia" (Hibou 2012), que es clave para comprender el cinismo con el que a veces se implementa el imperativo participativo y su carácter neoliberal en el sentido de que instala una moral desarraigada del contexto material en el que se pone en práctica. Esta práctica está directamente vinculada a que la participación, vía abstracción, pueda despolitizarse, creando un entrepreneurial citizen funcional al neoliberalismo (Baiocchi y Ganuza 2017: 6). Para el caso estudiado, subrayo las dos principales vías de abstracción que he identificado en el análisis; ambas revierten en una comprensión despolitizada de la participación: el uso de las normas ISO en la participación y el uso de conceptos esencialmente contestados.

En primer lugar, cabe matizar que uno de los grandes procesos de abstracción que ha canalizado la 
Tabla 4.

Ejemplos de textos jurídicos sobre la procedimentalización de la participación

\begin{tabular}{|c|}
\hline $\begin{array}{l}\text { NF 1/2017, de } 8 \text { febrero, de transparencia, participación ciudadana y buen gobierno del sector público del Territorio } \\
\text { Histórico de Álava) Artículo 62.- Acuerdo sobre la celebración de consultas populares: }\end{array}$ \\
\hline $\begin{array}{l}\text { 1. En los supuestos en los que la iniciativa para la realización de consultas populares corresponda a personas empadronadas } \\
\text { en el Territorio Histórico de Álava, la Diputación Foral resolverá sobre la iniciativa en el plazo de tres meses. El acuerdo deberá } \\
\text { ser motivado indicando, en caso de rechazo de la iniciativa, las razones por las que la Diputación Foral no considera oportuna la } \\
\text { realización de la consulta popular, entre las cuales puede estar que atente contra la igualdad de mujeres y hombres. }\end{array}$ \\
\hline $\begin{array}{l}\text { Ley } 5 / 2010 \text {, de } 21 \text { de junio, canaria de fomento a la Participación ciudadana. Artículo 12.- Derecho a la propuesta de } \\
\text { iniciativa reglamentaria: }\end{array}$ \\
\hline $\begin{array}{l}\text { 1. Los ciudadanos podrán presentar a la Administración autonómica y en materia de su competencia, propuestas de iniciativas } \\
\text { que afecten a sus derechos e intereses legítimos, proponiendo su tramitación como disposición reglamentaria (...) } 4 \text {. La Comisión } \\
\text { de secretarios generales técnicos es el órgano competente para, mediante acuerdo motivado, admitir o inadmitir la tramitación de } \\
\text { la propuesta de disposición reglamentaria } 5 \text {. Contra el acuerdo, expreso o presunto, de inadmisión a trámite de la propuesta de } \\
\text { solicitud de disposición reglamentaria no cabrá recurso alguno. }\end{array}$ \\
\hline Borrador de la Ley de Participación de Castilla-La Mancha. Art 14.3: \\
\hline $\begin{array}{l}\text { El pronunciamiento adoptado (resultado del proceso de deliberación participativa) se publicará por los mismos medios o canales } \\
\text { que la Resolución Básica Participativa y no será susceptible de recurso alguno, sin perjuicio del que proceda contra la resolución } \\
\text { aprobatoria del plan o contra la disposición general. }\end{array}$ \\
\hline
\end{tabular}

Fuente: Elaboración propia

nueva gestión pública se encuentra en las normas ISO (Hibou 2012). Actualmente, somos capaces de identificar ISO 9000 con calidad, o ISO 14000 con el medio ambiente. Con la ISO entra, también, una racionalidad que parece incontestable. Aunque actualmente no existe un estándar internacional de calidad sobre la participación, sí existen nuevas ISO que introducen la participación como variables independientes centrales que ya funcionan en España. Entre ellas, destaca la ISO 18091:2014: Gobiernos Locales Confiables, que busca responder a la "crisis de la democracia" y que es aplicada por empresas privadas, como Intedya ${ }^{\circledR}$, que buscan asegurar el ejercicio de los derechos constitucionales y la mejora de la calidad de vida y la justicia social. Esta norma ha sido aplicada en Xátiva (Valencia), Sant Fost de Campsentelles (Cataluña) y Tavernes de la Valldigna (Valencia), donde agentes con intereses privados (consultorías) se convierten en garantes de los principios de un Estado de derecho. Podemos decir que nos encontramos ante una externalización de las actividades nucleares del Estado vía participación.

En segundo lugar, el ejercicio de abstracción también se hace mediante "conceptos esencialmente contestados" (Gallie 1955), como el concepto de 'personas interesadas'. Un ejemplo de esta forma del uso de la abstracción lo tenemos en el art. 13.2 de la NF 1/2010 de la DFG que se reproduce a continuación. En él, las aparentes posibilidades que abre la imprecisión de quiénes son "las personas residentes que se consideren afectadas" chocan con la demarcación del ámbito territorial de afectación por la autoridad. Si nos fijamos en el texto reproducido a continuación, vemos que existe un importante desajuste en términos de oportunidad participativa entre las partes marcadas en cursiva y la frase subrayada:
Tendrán, asimismo, derecho de iniciativa para la realización de procesos de deliberación participativa, las personas residentes en el Territorio Histórico de Guipúzcoa que se consideren afectadas por la política o decisión a adoptar por la Diputación Foral y que representen, al menos, el dos por ciento de las personas residentes mayores de edad del conjunto del Territorio Histórico o del municipio o comarca que resulte afectado de forma especialmente relevante por aquella. A estos efectos, la Diputación Foral establecerá el ámbito territorial de afectación del mismo (art. 13.2 de la NF 1/2010 de la DFG).

Pareciera que quiere construirse una ciudadanía participativa y un ethos participativo sobre el principio de libertad individual omitiendo que la libertad viene marcada por las disposiciones jurídicas de un Estado liberal en el que no todos los agentes tienen las mismas condiciones para intervenir. Para ello, es importante ofrecer un tipo de participación a la carta, individualizado al estilo del do-it-yourself (Lee 2015).

\section{INDIVIDUALIZACIÓN DE LA PRÁCTICA PARTICIPATIVA Y RUPTURA DE LA LÓGICA COMUNITARIA}

Una característica del proyecto neoliberal es, como indicaba más arriba, el fortalecimiento del individualismo, pero no cualquiera, sino el que no permite prácticas contextualistas solidarias (Slobodian 2018; Bourdieu 1998). Si nos detenemos en la evolución de las herramientas para canalizar la participación que proponen las normas y leyes sobre participación en España, y que sistematizo en la tabla V, a partir del 2010 se aprecian, además del apego y mantenimiento de los canales del consejo, el derecho de petición, la Junta Municipal de Distrito 
Tabla 5.

Resumen de las principales herramientas de participación recogidas en los 76 textos jurídicos estudiados

1978 Referéndum consultivo (C.E)

1980 Consulta vía referéndum (L.O 2/1980)

1984 Iniciativa Legislativa Popular -ILP en adelante- (L.O. 3/1984)

ILP (L 4/1984, Asturias)

ILP Aragón (L. 7/1984)

1985 Consulta popular (L. 7/1985, LRBRL)

Consejo Escolar del Centro/ Consejo Escolar del Estado (L.O. 8/1985)

ILP Cantabria (6/1985)

ILP Castilla la Mancha (2/1985)

ILP Extremadura (7/1985)

ILP La Rioja (3/1985)

ILP Navarra (L foral 4/1985)

1986 Juntas Municipales de Distrito (RD 2568/1986)

Consejos Sectoriales (RD 2568/1986)

Exposición en el pleno (RD 2568/1986)

Oficina de Información (RD 2568/1986)

Peticiones de información (RD 2568/1986)

Consejo de Salud de la CCA.A (L. 14/1986)

II.P Canarias (10/1986)

II. C Comunidad de Madrid (6/1986)

1987 Servicio Municipal de Información. Reglamento de la FEMP:

Subvención asociaciones

Escucha pleno

Consejo Municipal de entidades

Consejos sectoriales o de área

Iniciativa ciudadana

Consulta popular

Consejo abierto (mumicipio $<20.000$ habs.)

Alcaldias de barrio

Junta municipal de vecinos

Asamblea geveral de vecinos (previa inscripción)

Comisiones de trabajo informativas

Junta de distrito

Participación en entes de servicios públicos mumicipales

1991 ILP Baleares (L. 4/1991)

1997 Consulta pública (L. 50/1997)

2001 Consejo nacional del agua (RDL 1/2001)

Derecho de petición, sugerencia, iniciativa, información, queja o súplica)

Consultas populares (L. 2/2001. Andalucía)

II.P Castilla y León (4/2001)

2002 Derecho de asociación (L.O 1/2002)

Consejos Sectoriales de asociación (L.O1/2002)

Fundación como herramienta (L. 50/2002)

Consultas populares en el ámbito local (Ley Foral Navarra 27/2002

2003 Consejo de Participación Social (L. 16/2003)

Consejos de distrito (L. 57/2003)

2005 Consejo de Ciudad. Reglamento Municipal de Participación Cindadana Tipo FEMP, RMPC Tipo FEMP :

Consejos Territoriales

Consejo de Niños y Niñas

Proceso participativo con utilización de metodologias participativas (Capitulo IV)
2006 Consejo Asesor de Medio Ambiente (L. 27/2006)

II.P Cataluina $(1 / 2006)$

ILP Murcia (9/1984 modificada por 7/2006)

2007 Proceso de participación por fases (Art 24, RMPC Córdoba):

Junta Municipal de Distrito

Consejo de Distrito

Consejo del Movimiento Cindadano

Asamblea de Ciudad

Consejo Infantil

2008 Patrocinio, cesiones de bienes públicos, apoyo técrico y difusión, ayudas economicas, medidas para la sensiblización y formación del persoual público (Art. 7)(Ley 11/2008 de participación ciudadana en Valencia)

Audiencias, foros de consulta, jurados cindadano5, encuestas de satisfaccion de servicios, web interactivas, observatorios, sesiones de preguntas y respuestas (Art. 19. Ley 11/2008 de participación ciudadana en Valencia)

2010 Consulta mediante sondeos, encuestas y otros instrumentos demoscópicos (Art. 20. Ley 5/2010 Fomento de la participación Canaria)

Foro de consulta pública (art. 21. Ley 5/2010)

Paneles cindadanos (Art. 22. Ley 5/2010)

Jurados ciudadanos (Art. 23. Ley 5/2010)

Consulta popular vía referéndum (Ley 4/2010 Cataluña)

Procesos de deliberación participativa (Norma Foral 1/2010):

Consultas populares

Participacion en la elaboración de anteproyectos de Normas Forales

Presupuestos participativos

2011 Presupuestos participativos (Art. 6.1.f L. 4/2011 de Buena Admón. de Baleares)

Encuestas, sondeos y paneles cindadanos (art. 6.2.L. 4/2011)

IIP (8/2011) Andalucía Modifica 5/1988

2012 Conversación telemática bidireccional. Escucha por canales telemáticos y telefónicos. Communicación a través de móviles (Ley Foral 11/2012 transparencia y Gob. Abjerto Navarra)

Foros de consultas (Ley Foral 11/2012)

Paneles ciudadanos (Ley Foral 11/2012)

2013 Conversación telemática bidireccional Escucha por canales telemáticos y telefónicos. Comunicación a través de móviles (Ley Foral 11/2012 transparencia y Gob. Abierto Navara)

Foros de cousultas (Ley Foral 11/2012)

Paneles ciudadanos (Ley Foral 11/2012)

2014 Participación en la elaboración de normas (Ley 19/2014 Transparencia. Cataluña)

Procesos de participación cindadana por fases (Ley 10/2014 de consultas no referendarias. Cataluña)

Andiencias públicas ciudadanas (Ley 10/2014)

Foros de participación (Ley 10/2014. Catalunia)

Consultas públicas (Ley 12/2014 Transparencia y PC Murcia)

Iniciativa ciudadana (Ley 12/2014)

Proceso de deliberación participativa (Ley 12/2014)

Conseio asesor regional de Murcia (Lev 12/2014) 
2015 Participación a través de la consulta de la opinión a partir de la información publicada en el portal web de la administración pública (L. 39/2015)

Consultas a través de audiencia pública, foro de consulta, paneles ciudadanos o jurados ciudadanos (art. 53. L. 8/2015 transparencia Aragón)

Procesos de deliberación participativa a través de debate público (art. 54. L. 8/2015)

Encuestas y estudios de opinión (art. 55. L. 8/2015)

Participación a través del Portal del Gobierno Abierto (Ley 3/2015 Transparencia. Castilla y León)

Consejo de Participación Ciudadana (Ley 2/2015 Transparencia. Valencia. Especialmente interesado en el uso de las nuevas tecnologías art. 46.2.)

ILP Galicia (7/2015)

2016 Consulta pública (Orden Pre 1590/2016)

Audiencia Pública (Orden Pre 15/2016)

Procesos de deliberación participativa(Proyecto de Ley de Gobierno Abierto, Participación y transparencia de la Comunidad de Madrid)

Procesos de deliberación participativa (previo acuerdo de deliberación participativa) (Ley 2/2016 Instituciones Locales Euskadi):

Participación ciudadana en la identificación de compromisos de gasto público en los presupuestos municipales

Consultas populares

Consultas sectoriales o de ámbito territorial limitado

Consultas ciudadanas abiertas para temas de especial relevancia

ILP Euskadi (10/2016)
2017 Presupuestos participativos (P.L. Participación Ciudadana en Andalucía):

Proceso de participación ciudadana tipo deliberación participativa

Proceso de participación ciudadana tipo proposición de políticas públicas y elaboración de normas

Proceso de participación ciudadana tipo seguimiento y evaluación de políticas públicas

Procedimiento de deliberación participativa (Borrador Castilla la Mancha)

Procesos participativos (Norma Foral de transparencia. Álava)

Procesos participativos organizados por fases, con órganos y regulación de formato de debates (RMPC Barcelona):

Consejo de Ciudad

Consejos de barrio

Audiencias Públicas

Intervenciones orales en consejo municipal y de distrito

Consultas ciudadanas

ILP Valencia (Ley 10/2017 que deroga 5/1993)

Fuente: Elaboración propia

y la novedad que supone el proceso de deliberación participativa, dos nuevas tendencias. La primera, la adopción de técnicas demoscópicas (sondeos, encuestas de satisfacción, paneles ciudadanos, "para garantizar la consulta periódica de los ciudadanos") cuya unidad de trabajo es el individuo. La segunda, la introducción de los procesos de participación virtuales, como las conversaciones telemáticas bidireccionales, fundamentalmente de la mano de los Portales de Gobierno Abierto.

Estas nuevas inclusiones han permitido la institucionalización de lo que Dominique Cardon (2011) denomina "esfera pública restringida", característica de una ciudadanía liberal y de una lógica neoliberal de gestión del espacio público, en la que la ciudadanía establece una comunicación web individualizada y privativa con la Administración que permite el diálogo entre distintas personas que tienen acceso web desde la intimidad de sus hogares. Aquí cabría sostener que la individualización de la práctica participativa no se entiende sin las tecnologías de la información y la comunicación (TIC). Puede entenderse que las TIC permiten construir el halo de interés que recubre el desinterés, ya que la participación en píldoras, acotada en breves periodos de tiempo, fragmentada, desconectada, corta y puntual es una participación que no pone en cuestión los ritmos ni la estructura de poder sobre la que se asienta el proceso de toma de decisiones, sino que facilita canales para que una élite que conoce sus códigos se inscriba en él bajo el principio de flexibilidad, siendo esto más posible con un uso específico de las TIC.

\section{NORMALIZACIÓN DE LAS DISPOSICIONES MORALES DE LA PARTICIPACIÓN}

La sexta práctica de racionalización tiene que ver con que los productos de participación que se utilizan en la acción pública tienden a prescribir conductas morales que reflejan una visión neoliberal de la justicia, en cuanto que tratan de poner en suspenso el juicio, con una actitud neoempresarial de la gestión de lo público que se basa en la división entre gestión y política. Además, interesa subrayar que esa prescripción se hace con productos cada vez más diversos, tales como manuales, cursos, circulares y monografías de puestos de trabajo. Las prescripciones morales se amplían en con el número de canales que las vehiculan y son dibujadas por un mayor número de agentes, además del Estado, entre los que destacan las consultorías privadas o las empresas. Esta ampliación de canales y de agentes coincide con las lecturas sobre la 
burocratización neoliberal que hacen algunas autoras para el caso de Francia (Mazeaud y Nonjon 2018; Hibou 2012).

En España, esta tendencia se constata con claridad en las guías de participación estudiadas. Estos documentos, en cuyas bases se recoge el topos de la crisis, prescriben la actitud que tienen que tener tanto el o la agente técnico de la participación (ATP) como la ciudadanía durante su práctica (tabla VI). Importa señalar, en primer lugar, que el ethos basado en la suspensión del juicio facilita una postura comprensiva con los "inevitables" problemas sobre los que se sostienen las políticas neoliberales cuando hay que hacer una gestión de "escasez de recursos", afrontar la "falta de compromiso político" o "adaptarse al entorno". Quien así actúa, tiene mucho que ver con el ciudadano o la ciudadana liberal, empresario o empresaria de sí mismo/a, pretendidamente autónomo y racional que dibujan las teorías neoliberales de la gestión económica contra las que ensayan las y los teóricos/as críticos/as referidos/as más arriba (Fraser y Jaeggi 2018; Bronw 2015). En segundo lugar, que ese ethos se sostiene sobre la cultura de la profesionalización de la participación que hay quien han visto crecer en países como el Reino Unido entre 1990 y 2010 (Chilvers 2017: 116).

\section{PROFESIONALIZACIÓN (ELITISTA) Y SOFISTICACIÓN DE LA PARTICIPACIÓN}

Siendo la profesionalización un movimiento intrínsecamente burocrático, el sentido neoliberal de la burocratización que atribuyo aquí a la acción pública en participación tiene que ver con la profundización de dos matices, la del elitismo y la

Tabla 6.

Pautas o patrones comportamentales a los que se induce, extraídas de los manuales que afectan a aspectos de la conducta que debe de tener el o la agente técnico de participación.

\begin{tabular}{|c|c|}
\hline Pauta/ patrón & Texto literal extraído de los manuales y guías \\
\hline $\begin{array}{l}\text { FLEXIBILIDAD, NEUTRALIDAD, CAPACIDAD DE } \\
\text { PONER EN SUSPENSO EL JUICIO DE VALOR }\end{array}$ & $\begin{array}{l}\text { Escucha activa, flexibilidad en los planteamientos, respeto a las posiciones críticas, capacidad } \\
\text { de negociación, reconocimiento mutuo de las debilidades y capacidad para la creación conjunta } \\
\text { (FAMP, 2010: 20). }\end{array}$ \\
\hline ADAPTABILIDAD & $\begin{array}{l}\text { Actitud abierta hacia conocimientos multidisciplinares y capacidad de adaptarse (FAMP, 2003: } \\
\text { 529). }\end{array}$ \\
\hline $\begin{array}{l}\text { CONFIANZA EN SI MISMO, CAPACIDAD DE } \\
\text { EMITIR UN JUICIO MORAL AUTÓNOMO Y } \\
\text { LIDERAZGO SIMBÓLICO }\end{array}$ & $\begin{array}{l}\text { En las reuniones públicas: "Confiar la presidencia a una persona que disponga de entereza, pero } \\
\text { también de capacidad de abertura, de preferencia una personalidad respetada, experimentada e } \\
\text { independiente con liderazgo y prestigio." (FAMP, 2003: 542). }\end{array}$ \\
\hline DISPOSICIÓN DE CAPITAL RELACIONAL & $\begin{array}{l}\text { Las personas encargadas de la animación local y de la coordinación de un proyecto, deben } \\
\text { ser capaces de comprender la naturaleza de los territorios y de sus estructuras, tanto formales } \\
\text { como informales; deben poder constituir un capital de confianza, crear redes de relaciones, } \\
\text { asociaciones, y conservar un espíritu abierto (FAMP, 2003: 548). }\end{array}$ \\
\hline $\begin{array}{l}\text { ALFABETIZACIÓN Y SENSIBILIDAD SOCIAL Y } \\
\text { HACIA EL ENTORNO }\end{array}$ & $\begin{array}{l}\text { Será preciso que quien proponga el eje de actuación tenga suficiente reconocimiento de } \\
\text { legitimidad y capacidad para llevarlo a la práctica y esta corresponda al interés de una gran parte } \\
\text { de los agentes locales. (FAMP, 2003: 562). }\end{array}$ \\
\hline $\begin{array}{l}\text { LIDERAZGO NATURAL, CARISMA, FORTALEZA, } \\
\text { CAPACIDAD DE CONTROLAR }\end{array}$ & $\begin{array}{l}\text { La persona que lidera un Círculo de Innovación debe transmitir la visión y la misión del Círculo } \\
\text { a todas las personas convocadas, pensar la estrategia, informar y, sobre todo, enseñar. Suele } \\
\text { actuar como moderadora natural, por lo tanto, es quien debe poner los temas, hacer hablar } \\
\text { a las personas poco participativas y controlar a las que quieren apoderarse de la reunión. } \\
\text { Posteriormente y en la medida en que no se vean afectada la reunión, el rol de moderador podrá } \\
\text { cederse a quien demuestre cualidades para ejercerlo. (...) La persona que lidere un Círculo de } \\
\text { Innovación debe: Hacer una labor de integración de las personas que constituyan el Círculo de } \\
\text { Innovación. Localizar formal e informalmente los roles de las personas componentes. Crear un } \\
\text { ambiente distendido, activo y positivo. Generar y consensuar unas normas básicas de conducta. } \\
\text { Aclarar y consensuar los objetivos. Delimitar las áreas de mejora. Una a una. No haga una } \\
\text { exposición múltiple. No olvidar la orientación colectiva de los objetivos. Nombrar secretario/a de } \\
\text { actas. Anotar todas las ideas que vayan surgiendo y especialmente los acuerdos, con nombres } \\
\text { y asuntos. Conseguir el consenso. Formalizar los impresos. Justificar todas sus propuestas con } \\
\text { criterios innovadores. Reforzar y reconocer todas las intervenciones. Controlar la reunión. No } \\
\text { permitir intervenciones negativas o descalificantes. Utilizar las herramientas para el análisis de } \\
\text { asuntos y para la toma de decisiones. Fomentar la participación de las personas más inhibidas. } \\
\text { (FAMP, 2005: 37). }\end{array}$ \\
\hline $\begin{array}{l}\text { CAPITAL RELACIONAL Y SENSIBILIDAD HACIA } \\
\text { EL ENTORNO }\end{array}$ & $\begin{array}{l}\text { Necesitamos un buen hacer técnico, un liderazgo facilitador (...) para impulsar y gestionar } \\
\text { procesos lo que se necesitan son más metodologías que normas (EUDEL, 2009: 30). }\end{array}$ \\
\hline $\begin{array}{l}\text { CAPITAL RELACIONAL, SERENIDAD, LIDERAZGO } \\
\text { Y RAPIDEZ MENTAL. INTELIGENCIA. }\end{array}$ & $\begin{array}{l}\text { La persona moderadora de la reunión debe tener las siguientes cualidades (inspirado en Ander } \\
\text { Egg). cordialidad, capacidad de escucha y empatía, sensibilidad, tacto y paciencia... Saber } \\
\text { integrar los antagonismos y manejar los conflictos, imparcialidad, no olvidar el sentido del humor, } \\
\text { pensamientos claros y rápidos, saber hacer preguntas... (FEMP, 2011: 53). }\end{array}$ \\
\hline
\end{tabular}

Fuente: Elaboración propia 
sofisticación, contrarios a la "profesionalización reflexiva" propuesta por quienes piensan que existe un diálogo posible entre burocracia y democracia que no esté mediado por el neoliberalismo (Chilvers 2017).

Esta séptima práctica de racionalización tiene una lógica elitista, porque encuentra su fuente de legitimación en la capacidad del trabajador y la trabajadora de demostrar la fortaleza de su capital cultural institucionalizado; demostrar que puede conectar con las normas de funcionamiento del campo político y establecer relaciones con el campo económico-financiero. El agente técnico valorado en el campo político es aquel que acumula un máster en Participación, conoce bien el derecho, tiene contactos en otros campos, especialmente en el económico y, en definitiva, tiene capacidad de previsión o "sentido práctico" de la participación. Esto se deduce de las guías de participación y las monografías de puestos de trabajo estudiadas, así como de las convocatorias de empleo público en materia de participación ( $v$. tabla I).

Asimismo, esta práctica tiene una lógica sofística porque se sostiene sobre la idea de un profesional aparentemente especializado en todo: aspectos técnicos, formales, comunicacionales, relacionales, retóricos. Es decir, un sabio de todo, un sabio de la apariencia, un sofista. Me refiero a la sofisticación para introducir la importancia que ha tomado en la práctica del ATP el arte retórico, así como las dimensiones comunicativas de su trabajo separadas de las relacionales. El giro neoliberal pasa porque la dimensión comunicativa tome entidad propia y se presente como un saber técnico adquirible. Un ejemplo de esto lo encontramos en la monografía de agente técnico municipal de animación de Gasteiz, en el que se requieren las siguientes habilidades:

"Poseer habilidad para evaluar el trabajo propio y el de los demás, orientando la evaluación en base a los resultados de los procesos ejecutados; Poseer habilidades de comunicación interpersonal (escucha, empatía, percepción de las necesidades del otro); Poseer capacidad de negociar acuerdos, de comunicar ayudando a otros a entender los contenidos de un proyecto; Poseer capacidad de iniciativa y creatividad; Ser capaz de obtener satisfacción personal del trabajo que se realiza; Ser capaz de mostrarse receptivo a las aportaciones que otros hacen a su trabajo, valorándolas adecuadamente; Ser capaz de tolerar la crítica racional que pueda recibir y poseer sentido autocrítico con una finalidad de mejorar; Poseer actitud de apertura y disposición hacia el aprendizaje continúo con la finalidad de permitir la incorporación de nuevos saberes actualizados; Poseer un rasgo personal de rigor y precisión"(Folio de la monografía de ATP de Gasteiz).

La mejora continua, la evaluación de resultados, el rigor y la fortaleza orientados a la eficiencia son rasgos definitorios de la idea de agente técnico ideal que algunas administraciones públicas han empezado a incorporar a sus plantillas. No puede escapársenos que estos ítems son los que constituyen el centro del lenguaje de la nueva gestión pública y del "nuevo espíritu del capitalismo" orientado por la lógica neoliberal (Baiocchi y Ganuza 2017; Boltanski y Chiapello 2002).

\section{CONCLUSIONES}

En este artículo me he interesado por la forma particular que adopta el giro participativo en España, para lo que he realizado un análisis genético de la institucionalización de la acción pública en participación entre 1978 y 2017 a través del estudio de una serie de productos políticos que constituyen hoy parte de la industria de la participación del país.

Tras el análisis del material empírico ( $v$. tabla I) he concluido, apoyándome en las interpretaciones marxianas del neoliberalismo (Slobodian 2018; Fraser y Jaeggi 2018; Brown 2015; Hibou 2012), que el giro participativo en España es de signo neoliberal, lo que implica una mayor presencia de las corporaciones empresariales privadas en la toma de decisión pública y una revalorización de la importancia del capital jurídico para diseñar las estructuras participativas de las instituciones. Concretamente, son tres los movimientos que me llevan a hacer tal afirmación.

El primero, la naturalización de un topos de la crisis de la democracia que permite a grandes corporaciones económicas filtrar sus productos de participación ciudadana orientados a la acumulación de capital. Asimismo, ese topos está diseñado a partir de una secuencia que integra una idea medicalizada de la participación.

El segundo movimiento es la burocratización neoliberal de la participación. En el texto, me he detenido en siete prácticas de racionalización particulares con las que se está llevando a cabo actualmente la burocratización de la participación en España. A este respecto, señalo la importancia de tener en consideración la paradoja del proyecto de desburocratizar la democracia burocratizando la participación. Asimismo, subrayo que no se trata, ahora, de eliminar toda práctica burocrática en el diseño institucional de la participación, sino de reflexionar sobre los efectos que tiene privilegiar la acumulación de capital jurídico y social en los agentes a la hora de integrar y diseñar un proceso participativo. Algo así como instituir una "burocracia reflexiva".

El tercer movimiento tiene que ver con la mercanti- 
lización privativa de la participación. Sabemos que el paso de la artesanía de la participación de la década de 1970 a la industria de la participación de los años 2010 ha dado como resultado distintos mercados de participación ciudadana (Mazeaud y Nonjon 2018). En el texto se han identificado el mercado social y el neoliberal. A este respecto, en investigaciones futuras orientadas a estudiar el funcionamiento del mercado de la participación ciudadana, no interesará tanto hacer un análisis descriptivo de las tendencias de cada mercado como realizar estudios sobre el uso que hacen los Estados de estos mercados y discernir el rol que juega la burocracia en ellos.

En estas páginas he trazado las principales líneas del diagnóstico al que remite la idea de GPN. Sin duda, han quedado muchos aspectos de cada uno de los movimientos del giro por profundizar. Me he querido centrar con más detenimiento en uno de los movimientos, la burocratización de la participación, por el reto en el que se encuentra la participación en este país de tener que conservar su radicalidad en pleno proceso de modernización administrativa, a través de programas de la nueva gestión pública en los que la crítica a la burocracia tiende a resolverse con más burocracia (Baiocchi y Ganuza 2017; Hibou 2012). En adelante, queda seguir profundizando en cada uno de los movimientos aquí mencionados estudiando con mayor profundidad algunos instrumentos de la puesta en marcha de la acción pública que en este trabajo han quedado descuidados; entre ellos, destaco los convenios de colaboración, enmarcados en procedimientos de externalización de la participación ciudadana, entre administraciones públicas de distinta escala y terceros agentes. Del estudio sistemático de estos y otros documentos importantes para el funcionamiento de la Administración, calcularemos con más precisión la intensidad con la que el neoliberalismo participativo desmantela la democracia.

\section{BIBLIOGRAFÍA}

Baiocchi, G., y E. Ganuza. 2017. Popular Democracy. The Paradox of Participation. California: Stanford University Press. https://doi.org/10.1515/9781503600775

Bezes, P. 2020. "Le nouveau phénomène bureaucratique: Le gouvernement par la performance entre bureaucratisation, marché et politique". Revue française de science politique 70: 21-47. https://doi.org/10.3917/ rfsp.701.0021

Bherer, L. et al. 2017. Professionalization of Public Participation M. Gauthier y L. Simard. Nueva York: Routledge. https://doi.org/10.4324/9781315637983

Bourdieu, P. 1966. "Champ intellectuel et projet créateur". Les Temps modernes 246: 865-906.

Bourdieu, P. 1997. "Le neoliberalisme comme revolution conservatrice". Interventions 1961-2001: 349-355.

Bourdieu, P. 1999. "Le fonctionament du champ intellectual". Regards sociologiques 17/18: 5-27.
Bourdieu, P. 2013. "Séminaires sur le concept de champs, 1972-975". Actes de la Recherche en Sciences Sociales 2013/5 200: 4-37. https://doi.org/10.3917/ arss.200.0004

Bourdieu, P. y L. Wacquant. 1998. "Sur les ruses de la raison impérialiste". Actes de la recherche en sciences sociales 121: 109-118. https://doi.org/10.3406/ arss.1998.3250

Boltanski, L. y E. Chiapello. 2002. El nuevo espíritu del capitalismo. Madrid: Akal.

Brown, W. 2015. Undoing the Demos. New York: Zone Books. https://doi.org/10.2307/j.ctt17kk9p8

Cardon, D. 2010. La démocratie Internet, promesses et limites. Paris: Seuil-La République des idées.

Chilvers, J. 2017. "Expertise, professionalization and reflexivity in mediating public participation". Pp. 115- 138 in Professionalization of Public Participation, editado por L. Bherer, M. Gauthier y L. Simard. Nueva York: Routledge. https://doi.org/10.4324/9781315637983-6

Clarke J y J. Newman. 1997. The Managerial State. Power, Politics and Ideology in The Remaking of Social Welfare. Londres: Sage.

Fraser, N. y R. Jaeggi. 2019. Capitalismo. Una controversia desde la Teoría Crítica. Morata: A Coruña.

Gallie, W. B. 1955. "Essentially Contested Concepts. Proceedings of the Aristotelian Society". Oxford University Press on behalf of The Aristotelian Society New Series 56: 167-198. https://doi.org/10.1093/aristotelian/56.1.167

Ganuza, E. 2010. "Les origines des budgets participatifs". Pp. 23-42, in La démocratie participative inachevée: Genèse, adaptations et diffusions Editado por MH Bacqué e Y. Sintomer. Saint-Etienne: Yves Michel.

Ganuza, E. y M. Fernández 2012. "El giro participativo de la administración”. Cuadernos de trabajo social 25: 333-343.

Harvey, D. 2014. Diecisiete contradicciones y el fin del capitalismo. Madrid: Traficantes de Sueños.

Hendriks, C. y L. Carson. 2008. "Can the market help the forum? Negotiating the commercialization of deliberative democracy". Policy Science 41: 293-313. https://doi. org/10.1007/s11077-008-9069-8

Hibou, B. 2012. La bureacratisation du monde à' l'ére néoliberale. Paris: La Découvérte. https://doi.org/10.3917/ dec.hibou.2013.01 PMid:24059148

Hüller, T. 2010. "Playground or Democratisation? New Participatory Procedures at the European Commission". Swiss Political Science Review 161: 77-107. https:// doi.org/10.1002/j.1662-6370.2010.tb00153.x

Illich, I. 1975. Némesis médica. Barcelona: Barral editores.

Lascoumes, P. y P. Le Galès. 2005. "Introduction: L'action publique saisie par ses instruments". Pp. 11-44 in Gouverner par les instruments, editado por P. Lascoumes. Paris: Presses de Sciences Po. https://doi. org/10.3917/scpo.lasco.2005.01.0011

Lawrence, T. B. y R. Suddaby. 2006. "Institutions and institutional work". Pp. 215-254 in The SAGE handbook of organization studies, editado por S. Clegg et al. Londres: Sage Publications. https://doi. org/10.4135/9781848608030.n7 PMid:17141354

Lee, C. 2015. Do-It-Yourself Democracy: The rise of the public engagement industry. New York, NY: Oxford University Press. https://doi.org/10.1093/acprof:oso/9780199987269.001.0001

Navarro, C. 1999. El sesgo participativo. Madrid: CSIC. 
Martínez-Palacios. 2021. El giro participativo neoliberal. Leioa: UPV/EHU servicio editorial.

Mazeaud, A. y M. Nonjon. 2018. Le marché de la démocratie participative. Paris: Editions du croquant.

Nonjon, M. 2005. "Professionnels de la participation: savoir gérer son image militante". Politix, vol. 70: 89-112. https://doi.org/10.3917/pox.070.0089

Ramió, C. 2016. "Una propuesta de postburocracia: Un modelo burocrático y empresarial". GIGAPP Working Papers 13: 1-32.
Slobodian, Q. 2018. Globalist. The end of Empire and the Birth of neoliberalism. USA: Harvard. https://doi. org/10.4159/9780674919808

Tholen, B. 2015. "Citizen participation and bureaucratization: the participatory turn seen through a Weberian lens". International Review of Administrative Sciences 81: 585-603. https://doi. org/10.1177/0020852314548152

Young, I.M. 2000. Inclusion and Democracy. Oxford: Oxford University Press. .

\section{NOTAS}

[1] Esta investigación ha sido realizada entre 2016 y 2019, y ha constituido el ejercicio de investigación presentado al concurso de acceso al cuerpo de Profesorado Titular de Universidad TUC8/1-D00110-11.

[2] En el texto me refiero a la noción bourdiana de 'campo', ampliamente definida como un espacio social en el que los agentes sociales luchan por lograr y acumular bienes raros, es decir, las distintas formas en las que se expresa el capital (Bourdieu 1966; 1999; 2013, entre otros).

[3] Cursivas de la autora.

\section{ANEXOS}

\section{Anexo I. Relación de leyes analizadas}

\section{Declaraciones internacionales firmadas por el Estado español}

1. Declaración Universal De Los Derechos Humanos, 1948

2. Pacto Internacional De Derechos Civiles Y Políticos, 1966

3. Convenio de Aarhus sobre acceso a la información, participación pública en la toma de decisiones y acceso a la justicia en materia de medio ambiente, 1998.

\section{Textos jurídicos producidos a escala Estatal}

4. Constitución Española, 1978

5. Ley Orgánica $2 / 1980$, de 18 de enero, sobre regulación de las distintas modalidades de referéndum

6. Ley Orgánica $3 / 1984$, de 26 de marzo, reguladora de la Iniciativa Legislativa Popular

7. Ley $7 / 1985$, de 2 de abril, de Regulación de Bases del Régimen Local (LRBRL)

8. Ley Orgánica 8/1985, de 3 de julio, reguladora del Derecho a la Educación

9. Ley $14 / 1986$, de 25 de abril, General de Sanidad

10. Real Decreto 2568/1986, de 28 de noviembre, por el que se aprueba el Reglamento de Organización, Funcionamiento y Régimen Jurídico de las Entidades Locales.

11. STC 119/1995 de 17 de julio (Tribunal Constitucional, Sala Segunda) RTC/1995/119

12. Ley 50/1997, de 27 de noviembre, del Gobierno

13. Real Decreto Legislativo 1/2001, de 20 de julio, por el que se aprueba el texto refundido de la Ley de Aguas

14. Ley Orgánica 4/2001, de 12 de noviembre, reguladora del Derecho de Petición

15. Ley Orgánica 1/2002, de 22 de marzo, reguladora del Derecho de Asociación

16. Ley $50 / 2002$, de 26 de diciembre, de Fundaciones

17. Ley $16 / 2003$, de 28 de mayo, de Cohesión y Calidad del Sistema Nacional de Salud

18. Ley $57 / 2003$, de 16 de diciembre, de medidas para la modernización del gobierno local (Ley de Grandes Ciudades)

19. Ley 27/2006, de 18 de julio, reguladora de Derechos de Acceso a Información, Participación Pública y Acceso a Justicia en materia medioambiental

20. Ley 45/2007, de 13 de diciembre, de Desarrollo Sostenible en el Medio Rural 
21. Ley $19 / 2013$, de 9 de diciembre, de transparencia, acceso a la información pública y buen gobierno

22. Ley 39/2015, de 1 de octubre, del Procedimiento Administrativo Común de las Administraciones Públicas

23. Real Decreto Legislativo $7 / 2015$, de 30 de octubre, por el que se aprueba el texto refundido de la Ley de Suelo y Rehabilitación Urbana

24. Orden PRE/1590/2016, de 3 de octubre, por la se publica el Acuerdo del Consejo de Ministros de 30 de septiembre de 2016, por el que se dictan instrucciones para habilitar la participación pública en el proceso de elaboración normativa a través de los portales web de los departamentos ministeriales

\section{Textos a nivel autonómico y por Comunidades Autónomas}

25. Carta de Zaragoza para la promoción de la participación ciudadana en el ámbito autonómico, 2016 Andalucía

26. Ley $5 / 1998$, de 17 de octubre, de iniciativa legislativa popular y de los ayuntamientos de Andalucía

27. Ley $2 / 2001$, de 3 de mayo, de regulación de las consultas populares locales en Andalucía

28. Proyecto de ley de participación ciudadana de Andalucía, 2016

Asturias

29. Ley $4 / 1984$, de 5 de junio, reguladora de la iniciativa legislativa de los Ayuntamientos y de la iniciativa popular

30. Proyecto de Ley del Principado de Asturias de transparencia y buen gobierno, 2014

31. Libro Blanco de la Participación Ciudadana del Principado de Asturias, 2017

Baleares

32. Ley 4/1991, de 13 de marzo, reguladora de la Iniciativa Legislativa Popular en las Islas Baleares

33. Ley 4/2011, de 31 de marzo, de la buena administración y del buen gobierno de las Illes Balears

Aragón

34. Ley $7 / 1984$, de 27 de diciembre, reguladora de la Iniciativa Legislativa Popular ante las Cortes de Aragón

35. Ley $8 / 2015$, de 25 de marzo, de transparencia de la actividad pública y participación ciudadana de Aragón

Canarias

36. Ley 10/1986, de 11 de diciembre, sobre Iniciativa Legislativa Popular de Canarias

37. Ley 5/2010, de 21 de junio, Canaria de Fomento de la Participación Ciudadana

Cantabria

38. Ley $6 / 1985$, de 5 de julio, de Iniciativa Legislativa Popular de Cantabria

39. Ley de Cantabria 4/2009, de 1 de diciembre, de Participación Institucional de los Agentes Sociales en el Ámbito de la Comunidad Autónoma

Castilla y León

40. Ley $4 / 2001$, de 4 de julio, reguladora de la Iniciativa Legislativa Popular y de los Ayuntamientos de Castilla y León

41. Ley $3 / 2015$, de 4 de marzo, de transparencia y participación ciudadana de Castilla y León

Castilla-La Mancha

42. Ley $2 / 1985$, de 8 de mayo, de Iniciativa Legislativa Popular y de los ayuntamientos de Castilla-la Mancha

43. Anteproyecto de Ley de Participación de Castilla-La Mancha, 2017

Cataluña

44. Ley $1 / 2006$, de 16 de febrero, de Iniciativa Legislativa Popular de Cataluña (2006)

45. Ley de Cataluña 4/ 2010, de 17 de marzo, de consultas populares por vía de referéndum

46. Decreto $200 / 2013$, de 23 de julio, de los consejos de participación territorial y nacional de los niños y los adolescentes de Cataluña 
47. Ley 19/2014, de 29 de diciembre, de transparencia, acceso a la información pública y buen gobierno

48. Ley $10 / 2014$, de 26 de septiembre, de consultas populares no referendarias y otras formas de participación ciudadana

Comunidad Valenciana

49. Decreto 76/2009, de 5 de junio, del Consell, por el que se aprueba el reglamento de desarrollo y ejecución de la Ley 11/2008, de 3 de julio, de la Generalitat, de participación ciudadana de la Comunitat Valenciana

50. Ley $2 / 2015$, de 2 de abril, de la Generalitat, de transparencia, buen gobierno y participación ciudadana de la Comunitat Valenciana

51. Ley $10 / 2017$, de 11 de mayo, de la Generalitat, por la que se regula la iniciativa legislativa popular ante Les Corts

\section{Extremadura}

52. Ley $7 / 1985$, de 26 de noviembre, de iniciativa legislativa popular de la Comunidad Autónoma de Extremadura

53. Ley $4 / 2013$, de 21 de mayo, de gobierno abierto de Extremadura

\section{Galicia}

54. Ley 4/2006, de 30 de junio, de transparencia y de buenas prácticas, en la Administración Pública Gallega

55. Ley $7 / 2015$, de 7 de agosto, de Iniciativa Legislativa Popular y participación ciudadana en el Parlamento de Galicia

La Rioja

56. Ley $3 / 1985$, de 20 de mayo, sobre Iniciativa Legislativa del pueblo riojano

57. Ley $3 / 2014$, de 11 de septiembre, de transparencia y buen gobierno de la Rioja

Madrid

58. Ley 6/1986, de 25 de junio, de Iniciativa Legislativa Popular de los Ayuntamientos de la Comunidad de Madrid

59. Proyecto de Ley de Gobierno Abierto, Participación Ciudadana y Transparencia de la Comunidad de Madrid, 2016

Murcia

60. Ley 9/1984, de 22 de noviembre, reguladora de la Iniciativa Legislativa Popular de los Ayuntamientos y Comarcas de la Región de Murcia

61. Ley $12 / 2014$, de 16 de diciembre, de transparencia y participación ciudadana de la Comunidad Autónoma de la Región de Murcia

\section{Navarra}

62. Ley Foral 3/1985, de 25 de marzo, reguladora de la Iniciativa Legislativa Popular de Navarra

63. Ley Foral $27 / 2002$, de 28 de octubre, reguladora de consultas populares de ámbito local de Navarra

64. Ley Foral 11/2012, de 21 de junio, de la transparencia y del gobierno abierto

País Vasco

65. Norma Foral $1 / 2010$, de 8 de julio, sobre participación ciudadana (Gipuzkoa)

66. Libro blanco de democracia y participación ciudadana para Euskadi, 2014

67. Ley $2 / 2016$, de 7 de abril, de Instituciones Locales de Euskadi

68. Ley 10/2016, de 30 de junio, reguladora de la Iniciativa Legislativa Popular.

69. Norma Foral $1 / 2017$, de 8 febrero, de transparencia, participación ciudadana y buen gobierno del sector público del Territorio Histórico de Álava

70. Norma Foral 5/2018, de 12 de noviembre, sobre Participación Ciudadana de la DFG. 


\section{Reglamentos a nivel municipal}

71. Reglamento de Participación ciudadana de la FEMP 1987 (tres reglamentos distintos en función del número de habitantes del municipio)

72. Reglamento-Tipo De Participación Ciudadana Aprobado por la Comisión Ejecutiva de la FEMP el 26 de abril de 2005

73. Reglamento de participación ciudadana del Ayuntamiento de Córdoba, 2008

74. Reglament de participació ciutadana del Ayuntamiento de Barcelona, 2017

75. Reglamento Municipal de Participación Ciudadana del Ayuntamiento de Cádiz, 2017

76. Reglamento Municipal de Participación Ciudadana del Ayuntamiento de Pamplona, 2005

77. Reglamento Municipal de Participación Ciudadana del Ayuntamiento de Pamplona, 2019

\section{Anexo II. Relación de guías y manuales estudiados}

Se recogen a continuación las guías y manuales estudiados, clasificados por la federación de municipios desde la que se consultaron originalmente, en el momento de realizar la investigación.

\section{Asociació Catalana de Municipis i Comarques}

1. Brugué, Q., Pindado, F.; \& Rebollo, Ó. (2015). Democràcia local en temps d'incertesa. Barcelona: Asociació Catalana de Municipis i Comarques. https://www.acm.cat/actualitat/publicacions/08-democracia-local-en-temps-dincertesa

2. Jiménez Asensio, R. (2015). Bona governança i transparència municipal: Guia per a la implantació als ajuntaments de la Llei del Parlament de Catalunya 19/2014, de 31 de desembre. Barcelona: Asociació Catalana de Municipis i Comarques; Federació de Municipis de Catalunya. http://www.acm.cat/sites/ default/files/manual_uploads/transparencia/guia_bona_governanca_i_transparencia_municipal.pdf

3. Moles Plaza, R. J. (dir.) (2011). Anàlisi dels elements del bon govern local: codi del bon govern local. Barcelona: Asociació Catalana de Municipis i Comarques. https://www.acm.cat/actualitat/publicacions/04-analisi-dels-elements-del-bon-govern-local

\section{EUDEL - Euskadiko Udalen Elkartea}

4. Elhuyar Aholkularitza (2006). Jardunaldia: herritarren parte-hartzea: zeharkako estrategia tokiko politiketan = Jornada: participación ciudadana: estrategia transversal en las políticas locales. Vitoria-Gasteiz: Euskadiko Udalen Elkartea. https://www.eudel.eus/es/documentos/documento_de_conclusiones__ornada_participacion_ciudadana_estrategia_transversal_en_las_politicas_locales_

5. Euskadiko Udalen Elkartea (2009). ¿Cómo realizar un proceso participativo de calidad?: Guía práctica. Vitoria-Gasteiz: EUDEL. https://www.eudel.eus/es/file/libro_ficheros/GUIA_21.pdf

6. Euskadiko Udalen Elkartea (2010). eGobernanaza: participación ciudadana e innovación. Vitoria-Gasteiz: EUDEL. https://www.eudel.eus/es/file/libro_ficheros/eGobernanza.pdf

7. Euskadiko Udalen Elkartea (2010). Manual metodológico AlL (Agenda de innovación local). Vitoria-Gasteiz: EUDEL. https://www.eudel.eus/es/file/libro_ficheros/MANUAL_METODOLOGICO_AIL.pdf

8. Euskadiko Udalen Elkartea (2011). Glosario de herramientas para la innovación local. Vitoria-Gasteiz: EUDEL. https://www.eudel.eus/es/file/libro_ficheros/GLOSARIO\%20HERRAMIENTAS\%2OPARA\%20 LA\%20INNOVACION\%20LOCAL.pdf

\section{Federación Andaluza de Municipios y Provincias}

9. Agencia Andaluza de Voluntariado (2002). Manual de proyectos. Sevilla: Junta de Andalucía, Consejería de Gobernación. https://www.slideshare.net/wilincar/manual-de-proyectos-agencia-andaluza-del-voluntariado

10. Agencia Andaluza de Voluntariado (2006). Il Plan andaluz del voluntariado en Andalucía 2006-2009. Sevilla: Agencia Andaluza de Voluntariado. http://revalmeria.org/wp-content/uploads/2016/05/REVAL-2-Plan-Andaluz-Voluntariado.pdf

11. Agencia Andaluza de Voluntariado (2007). Guía de indicadores para identificar buenas prácticas. SeviIla: Agencia Andaluza de Voluntariado. 
12. Allegretti, G., Herzberg, C. (2004). El 'retorno de las carabelas': los presupuestos participativos de Latinoamérica en el contexto europeo. Papeles de la FIM, 23, 49-76. Fundación de Investigaciones Marxistas. http://www.famp.es/export/sites/famp/.galleries/documentos-obs-participacion/El_retorno_ de_las_carabelas.pdf

13. Ayuntamiento de Alcalá de Guadaira (2007). Plan director de ciudadanía. Alcalá de Guadaira: Ayuntamiento.

14. Cabannes, Y. (2007). Instrumentos de articulación entre presupuesto participativo y ordenamiento territorial: una síntesis basada en las experiencias de Ariccia (Italia); Belo Horizonte y Guarulhos (Brasil); Bella Vista (Argentina) y Córdoba (España). Porto Alegre: Urb-AL. http://www.famp.es/export/sites/ famp/.galleries/documentos-obs-participacion/PpyOrd.Territorial.pdf

15. Castellá Andreu, J. A. (2010). Descentralización política y democracia en España: la ley catalana de consultas populares por la vía de referéndum, un intento frustrado de ampliar los derechos de participación en el plano autonómico. Sevilla: Federación Andaluza de Municipios y Provincias. http://www.famp. es/export/sites/famp/.galleries/documentos-obs-participacion/referendums.pdf

16. Colombo, C. (2006). Innovación democrática y TIC, ¿hacia una democracia participativa? IDP: revista de Internet, derecho y política = revista d'Internet, dret i política, 3, 28-40. https://dialnet.unirioja.es/ descarga/articulo/2119691.pdf

17. Comisión Europea (2001). La gobernanza europea: un libro blanco: COM (2001) 428 final (2001/C 287/01). Bruselas: Comisión Europea. https://eur-lex.europa.eu/legal-content/ES/TXT/PDF/?uri=CELEX:52001DC0428\&from=ES

18. Comité de las Regiones de la Unión Europea (2009). Libro blanco del Comité de las Regiones sobre la gobernanza multinivel. Bruselas: Comité de las Regiones de la Unión Europea. https://www.europarl. europa.eu/meetdocs/2009_2014/documents/regi/dv/cdr89-2009_/cdr89-2009_es.pdf

19. Del Pino, E., Colino, C. (2007). Un fantasma recorre Europa: renovación democrática mediante iniciativas de promoción de la participación ciudadana en los gobiernos locales (Alemania, Francia, Reino Unido y España). Madrid: Consejo Superior de Investigaciones Científicas, Unidad de Políticas Comparadas. http://hdl.handle.net/10261/1681

20. Federación Andaluza de Municipios y Provincias (2003). Materiales de apoyo para los/as técnicos/as de desarrollo local. Sevilla: Federación Andaluza de Municipios y Provincias. https://www.um.es/observalocal/?smd_process_download=1\&download_id=31371

21. Federación Andaluza de Municipios y Provincias (2005). Participando, creando, e innovando: un enfoque local. Sevilla: Federación Andaluza de Municipios y Provincias. http://documentos.famp.es/documentacion/publicaciones/2005Participando.pdf

22. Federación Andaluza de Municipios y Provincias (2006). Glosario abierto de participación ciudadana. Sevilla: FAMP. http://www.famp.es/export/sites/famp/.galleries/documentos-obs-participacion/GLOSARIO-ABIERTO-DE-PARTICIPACION-CIUDADANAx1.pdf

23. Federación Andaluza de Municipios y Provincias (2007). Entornos saludables: las ciudades del siglo XXI: guía de buenas prácticas. Sevilla: FAMP.

24. Federación Andaluza de Municipios y Provincias (2010). Guía práctica para la implementación de la participación ciudadana en los gobiernos locales de Andalucía: estrategias para la acción. Sevilla: FAMP. https://studylib.es/doc/1014443

25. Federación Andaluza de Municipios y Provincias (2011). Programa Conciliam 2009-11. Sevilla: FAMP.

26. Federación Española de Municipios y Provincias (2006). Agenda local para la participación (aprobado por la Comisión ejecutiva de la FEMP el 19 de diciembre de 2006). Madrid: FEMP. https://www.dipucadiz.es/export/sites/default/participacion_ciudadana/.galeria-de-ficheros/documentos/Agenda-Local-para-la-Participacin-alapar.pdf

27. Font, J. (2004). Participación ciudadanía y decisiones públicas: conceptos experiencias y metodologías. En A. Ziccardi (coord.), Participación ciudadana y políticas sociales en el ámbito local (pp. 23-42), México: Instituto de Investigaciones Sociales de la Universidad Nacional Autónoma de México, Instituto Nacional de Desarrollo Social, Consejo Mexicano de Ciencias Sociales http://ru.iis.sociales.unam. $\mathrm{mx} / \mathrm{jspui} /$ bitstream/IIS/4420/1/Participacion $\% 20$ ciudadana $\% 20 \mathrm{y} \% 20$ politicas $\% 20$ sociales $\% 20 \mathrm{en} \% 20$ el\%20ambito\%20local.pdf 
28. Francés García, F., Carrillo Cano, A. (2008). Guía metodológica de los presupuestos participativos. Alicante: Preparacción. http://www.famp.es/export/sites/famp/.galleries/documentos-obs-participacion/t_ prepar_guia_metodologica.pdf

29. Goldfrank, B. (2012). Democracia participativa y sostenibilidad ambiental: una revisita a las lecciones de América Latina. Nueva Sociedad, 240, 87-109. https://www.nuso.org/media/articles/downloads/3882_1.pdf

30. Márquez, F., Sanhueza, A., De Ferari, M., Mujica, P., González, R.; \& Cáceres, M. C. (2001). Participación ciudadana en la gestión pública: marco conceptual. Santiago de Chile: Secretaría General de la Presidencia, Gobierno de Chile. http://www.famp.es/export/sites/famp/.galleries/documentos-obs-participacion/EL_ESTADO_AL_SERVICIO_DE_LOS_CIUDADANOS.pdf

31. Montecinos, E. (2012). Democracia y presupuesto participativo en América Latina: la mutación del presupuesto participativo fuera de Brasil. Revista del CLAD Reforma y Democracia, 53, 1-21. http://siare. clad.org/fulltext/0070200.pdf

32. Navarro Yañez, C.J., Pérez Boza, E. (2004). Las razones del voluntariado: solidaridad organizada en las capitales andaluzas. Sevilla: Agencia Andaluza de Voluntariado. https://www.upo.es/cms1/export/ sites/upo/upsc/voluntariado/oficina-voluntariado/documentos/1107766852494_razonesvol.pdf

33. Olivetti, M. (2012). La ordenación de la participación ciudadana en las regiones italianas. http://www. famp.es/export/sites/famp/.galleries/documentos-obs-participacion/Presentacion_PP_Italia_y_participacion.pdf

34. Parlamento Europeo, Consejo de la Unión Europea, Comisión Europea (2000). Carta de los derechos fundamentales de la Unión Europea. Bruselas: Parlamento Europeo, Consejo de la Unión Europea, Comisión Europea. https://www.europarl.europa.eu/charter/pdf/text_es.pdf

35. Pérez Alberdi, M. R. (2008). Los derechos de participación en los estatutos de autonomía reformados recientemente: especial consideración al Estatuto de Autonomía para Andalucía. Revista de Derecho Político, 73, 181-205. https://doi.org/10.5944/rdp.73.2008.9262

36. Pindado, F. (2005). La participación no se improvisa. Revista de Estudios Locales (CUNAL), 83, 93103. http://www.famp.es/export/sites/famp/.galleries/documentos-obs-participacion/La_participacion_ no_se_improvisa_-_Fernando_Pindado.pdf

37. Sintomer, Y., Ganuza Fernández, E., Carsten, H.; \& Röcke, A. (2011). Democracia participativa y modernización de los servicios públicos: investigación sobre las experiencias de presupuesto participativo en Europa. Amsterdam: Transnational Institute. http://www.iesa.csic.es/publicaciones/120120127.pdf

38. Unión Europea (2014). Ciudadanos con Europa.

\section{Federación Aragonesa de Municipios y Comarcas}

39. Bermejo Latre, J. L.; \& Castel Gayán, S. (Ed.) (2013). .Transparencia, participación ciudadana y administración pública en el siglo XXI. Zaragoza: Gobierno de Aragón, Departamento de Hacienda y Administración Pública. http://bibliotecavirtual.aragon.es/bva/i18n/catalogo_imagenes/grupo.cmd?path=3712809

40. Caurín, P., Ramo C.; \& Vivas, I. (2011). Guía-marco de la mediación en Aragón. Zaragoza: Gobierno de Aragón; Aragón Participa. http://aragonparticipa.aragon.es/sites/default/files/stories/2011/ACTUALIDAD/NOTICIAS/ARAGON/Mediacion/guawordfinaldef.pdf

41. Checa, E., Celaya, N., López, F., Castel, S., Escartín, J., Domínguez, G., Lostal, M., Viartola, P., Torralba, J. Cortés, A.; \& Verón, J. J. (2011). Memoria 2007-2011: Dirección General de Participación Ciudadana: 4 años de innovación democrática. Zaragoza: Gobierno de Aragón, Dirección General de Participación Ciudadana. http://aragonparticipa.aragon.es/sites/default/files/memoria_2007_2011_def.pdf

42. Deliberación: revista para la mejora de la calidad democrática. (2013), 3. Zaragoza: Gobierno de Aragón, Dirección General de Participación Ciudadana, Acción Exterior y Cooperación. http://bibliotecavirtual.aragon.es/bva/i18n/catalogo_imagenes/grupo.cmd?path=3715024

43. Deliberación: revista para la mejora de la calidad democrática. (2012), 2. Zaragoza: Gobierno de Aragón, Dirección General de Participación Ciudadana, Acción Exterior y Cooperación. http://bibliotecavirtual.aragon.es/bva/i18n/catalogo_imagenes/grupo.cmd?path $=3707890$

44. Deliberación: revista para la mejora de la calidad democrática. (2010), 1. Zaragoza: Gobierno de Aragón, Dirección General de Participación Ciudadana, Acción Exterior y Cooperación. http://bibliotecavirtual.aragon.es/bva/i18n/catalogo_imagenes/grupo.cmd?path=3707889 
45. Gobierno de Aragón, Departamento de Ciudadanía y Derechos Sociales (2017). Procesos de participación ciudadana para la elaboración de políticas públicas: memoria y evaluación de los talleres realizados en 2016. Zaragoza: Gobierno de Aragón, Departamento de Ciudadanía y Derechos Sociales. http://www. aragonparticipa.es/sites/default/files/memoria_datos_evaluacion_2016_13_marzo_2017.pdf

46. Gobierno de Aragón, Dirección General de Participación Ciudadana (2010). Cuaderno normativo de participación ciudadana. 1. Régimen jurídico de la participación ciudadana. Zaragoza: Dirección General de Participación Ciudadana. http://aragonparticipa.aragon.es/sites/default/files/cuaderno1.pdf

47. Gobierno de Aragón, Dirección General de Participación Ciudadana (2011). Cuaderno normativo de participación ciudadana. 2. Participación ciudadana en el ámbito local. Zaragoza: Dirección General de Participación Ciudadana. http://aragonparticipa.aragon.es/sites/default/files/cuaderno_normativo_local.pdf

48. Gobierno de Aragón, Dirección General de Participación Ciudadana, Acción Exterior y Cooperación (2010). Cuaderno metodológico de participación ciudadana. 1. Modelo para estructurar y desarrollar procesos de participación. Zaragoza: Dirección General de Participación Ciudadana Acción Exterior y Cooperación. http://aragonparticipa.aragon.es/sites/default/files/cuaderno_metodologico.pdf

49. Institut de Govern i Polítiques Públiques, Àrea de Participació i Moviments Socials (2009). Teoría y significado de la participación no institucionalizada en la comunidad de Aragón. Barcelona: Universitat Autònoma de Barcelona. http://aragonparticipa.aragon.es/sites/default/files/participacion_no_institucional_aragon.pdf

50. Moreno Jiménez. J. M. (2009). Participación ciudadana electrónica en el diseño de políticas públicas locales. Zaragoza: Gobierno de Aragón; Aragón Participa. http://aragonparticipa.aragon.es/sites/default/ files/participacion_ciudadana_electronica_1.pdf

51. Rebollo. O. (2010). La participación ciudadana en el ámbito local: reflexiones para desarrollar una política pública desde el Gobierno de Aragón. Zaragoza: Gobierno de Aragón; Aragón Participa. http:/l aragonparticipa.aragon.es/sites/default/files/informe_oscar_rebollo.pdf

52. Subirat Vila, J., Innerarity Grau, D., Tudela Aranda, J., Brugué Torruella, Q., Castel Gayán, S., Celaya Pérez, I., Pindado i Sànchez, F., López Martín, F. (2009). Participación ciudadana para una administración deliberativa. Zaragoza: Gobierno de Aragón, Dirección General de Participación Ciudadana. http:// aragonparticipa.aragon.es/sites/default/files/libro_dgpc.pdf

53. Tur Ausina, R. (2010). Bases para la ordenación de la participación ciudadana en Aragón: informe. Zaragoza: Gobierno de Aragón; Aragón Participa. http://aragonparticipa.aragon.es/sites/default/files/ informe_tur_.pdf

\section{Federación Española de Municipios y Provincias}

54. Ciudades y Gobiernos Locales Unidos, Comisión de Inclusión Social, Democracia Participativa y Derechos Humanos (2001). Carta-agenda mundial de derechos humanos en la ciudad. Madrid: Federación Española de Municipios y Provincias.

55. Federación Española de Municipios y Provincias (2003). Reglamento-marco de voluntariado local: documento aprobado por la Comisión Ejecutiva de la FEMP el 11 de marzo de 2003. Madrid: FEMP. http:/l femp.femp.es/files/566-330-archivo/REGLAMENTOMARCOVOLUNTARIADOLOCAL1.pdf

56. Federación Española de Municipios y Provincias (2005). Reglamento-tipo de participación ciudadana: aprobado por la Comisión Ejecutiva de la FEMP el 26 de abril de 2005. Madrid: FEMP. Disponible en: http://femp.femp.es/files/566-1596-archivo/Reglamento\%20tipo\%20FEMP\%20Participaci\%C3\%B3n\%20Ciudadana.pdf (consulta: 22 octubre 2020).

57. Federación Española de Municipios y Provincias (2009). Guía para la constitución de consejos municipales de las mujeres. Madrid: Federación Española de Municipios y Provincias. http://femp.femp.es/ files/566-181-archivo/Guia\%20constitucion\%20Consejos\%20Locales\%20de\%20Mujeres.pdf

58. Federación Española de Municipios y Provincias (2011). Modelo plan estratégico de voluntariado local. Madrid: FEMP. http://femp.femp.es/files/566-1163-archivo/PLAN\%20ESTRAT\%C3\%89GICO\%20 DE\%20VOLUNTARIADO\%20FEMP.pdf

59. Pindado Sànchez, F., Lizcano, J., Garmendia, G., Coma, T., Giner, C., Larragueta, M., Dirección General de Participación Ciudadana, Acción Exterior y Cooperación del Gobierno de Aragón, 
Comisión de Modernización, Participación Ciudadana y Calidad de la Federación Española de Municipios y Provincias (2015). Guía de instrumentos y herramientas para las políticas locales de transparencia y Participación Ciudadana. Madrid: Federación Española de Municipios y Provincias. http://femp.femp.es/files/566-1685-archivo/Guia\%20transparencia\%20y\%20participaci\%C3\%B3n\%20FEMP.pdf

\section{Federación Galega de Municipios e Provincias}

60. Federación Galega de Municipios e Provincias (2015). Plan de transparencia e bo goberno para entidades locais. Santiago de Compostela: FEGAMP. http://www.fegamp.gal/sites/default/files/artigos/descargas/plandetransparenciaebogobernoparaentidadeslocais.pdf

\section{Federación Navarra de Municipios y Concejos}

61. Antoñanzas, A. (2016). Estrategia de desarrollo local participativo en la zona media. Jornada sobre participación ciudadana y entidades locales, Pamplona, 20 mayo. Pamplona: Federación Navarra de Municipios y Concejos. http://www.fnmc.es/wp-content/uploads/sites/135/2016/05/CONSORCIO-ZONA-MEDIA-Alejandro-_Anto\%C3\%B1anzas.pdf

62. Ayuntamiento de Zarautz (2012). Zarauzko Udalaren herritarren parte-hartze eredua elkarrekin eraikiz = Construyendo juntos/as el modelo de participación ciudadana del Ayuntamiento de Zarautz. Jornada sobre participación ciudadana y entidades locales, 20 mayo 2016. Pamplona: Federación Navarra de Municipios y Concejos. http://www.fnmc.es/wp-content/uploads/sites/135/2016/05/ZARAUTZ.-Construyendo-juntos-el-Modelo-de-Participaci\%C3\%B3n.pdf

63. Ayuntamiento de Zarautz (2016). Zarauzko Udalaren herritarren parte-hartze eredua: eredua elkarrekin eraikiz: irizpide orokorrak = Modelo de participación ciudadana del Ayuntamiento de Zarautz: construyendo juntos/as el modelo: criterios generales. Jornada sobre participación ciudadana y entidades locales, Pamplona, 20 mayo. Pamplona: Federación Navarra de Municipios y Concejos. http://www.fnmc.es/ wp-content/uploads/sites/135/2016/05/ZARAUTZ.-Modelo-de-Participaci\%C3\%B3n-Ciudadana1.pdf

64. Azcona, P. (2016). Los presupuestos participativos en Lodosa. Jornada sobre participación ciudadana y entidades locales, Pamplona, 20 mayo. Pamplona: Federación Navarra de Municipios y Concejos. http://www.fnmc.es/wp-content/uploads/sites/135/2016/05/LODOSA.-Pablo-Azcona.pdf

65. Brugué, Q. (2016). Participación ciudadana en los gobiernos locales ¿entre el sueño y la pesadilla? Jornada sobre participación ciudadana y entidades locales, Pamplona, 20 mayo. Pamplona: Federación Navarra de Municipios y Concejos. http://www.fnmc.es/wp-content/uploads/sites/135/2016/05/ QUIM-BRUGU\%C3\%89-Universidad-Barcelona.pdf

66. Diputación Foral de Gipuzkoa (2009). Participación ciudadana institucional: comprender, practicar, impulsar la participación. Donostia-San Sebastián: Diputación Foral de Gipuzkoa. http://www.fnmc.es/wp-content/uploads/sites/135/2016/09/Guipuzkoa_Comprender_Practicar_Impulsar_la_Participacion_es.pdf

67. Federación Navarra de Municipios y Concejos (2016). Jornada sobre participación ciudadana en las entidades locales de Navarra. Pamplona: FNMC. http://www.fnmc.es/2016/05/25/presentaciones-jornada-participacion-ciudadana/

68. Mendoza, F.; \& del Rey, A. (2016). Aspectos prácticos novedosos del planeamiento: participación ciudadana: (modelo de buenas prácticas: Plan municipal de Arguedas). Jornada sobre participación ciudadana y entidades locales, Pamplona, 20 mayo. Pamplona: Federación Navarra de Municipios y Concejos. http://www.fnmc.es/wp-content/uploads/sites/135/2016/05/ARGUEDAS.-Fernando-Mendoza.pdf

69. Ollokiegi, N. (2016). Partaidetza arloko eskarmentua Zarautzen. Jornada sobre participación ciudadana y entidades locales, Pamplona, 20 mayo. Pamplona: Federación Navarra de Municipios y Concejos. http://www.fnmc.es/wp-content/uploads/sites/135/2016/05/ZARAUTZ.-Nerea-Ollokiegi.pdf

70. Organización para la Cooperación y el Desarrollo Económicos (a2001). Implicar a los ciudadanos en la elaboración de políticas: información, consulta y participación pública. PUMA: Nota de Políticas Públicas, 10. http://www.fnmc.es/wp-content/uploads/sites/135/2016/09//nforme-OCDE_Informaci\%C3\%B3n-y-participaci\%C3\%B3n_1.pdf

71. Organización para la Cooperación y el Desarrollo Económicos (2003). Un gobierno abierto: fomentar el diálogo con la sociedad civil. París: Organización para la Cooperación y el Desarrollo Económicos. http://www.fnmc.es/wp-content/uploads/sites/135/2016/09/fomentar-el-dialogo-con-la-sociedad.pdf 
72. Oroz, A.; \& Istúriz, E. (2016). La participación ciudadana en la Agenda Local 21 de Ansoáin. Jornada sobre participación ciudadana y entidades locales, Pamplona, 20 mayo. Pamplona: Federación Navarra de Municipios y Concejos. http://www.fnmc.es/wp-content/uploads/sites/135/2016/05/ANTSOAIN.-Ander-Oroz-y-Eva-Ist\%C3\%BAriz.pdf

73. Piedrafita, P. (2016). Donde empieza la ciudad: Los mecanismos de las Entidades Locales para el impulso y aplicación de la participación ciudadana. Jornada sobre participación ciudadana y entidades locales, Pamplona, 20 mayo. Pamplona: Federación Navarra de Municipios y Concejos. http://www. fnmc.es/wp-content/uploads/sites/135/2016/05/SABI\%C3\%91ANIGO.-Pilar-Piedrafita.pdf

ANEXo III. Sistema de CODIFICACIÓN de gUías de PARTICIPACIÓN

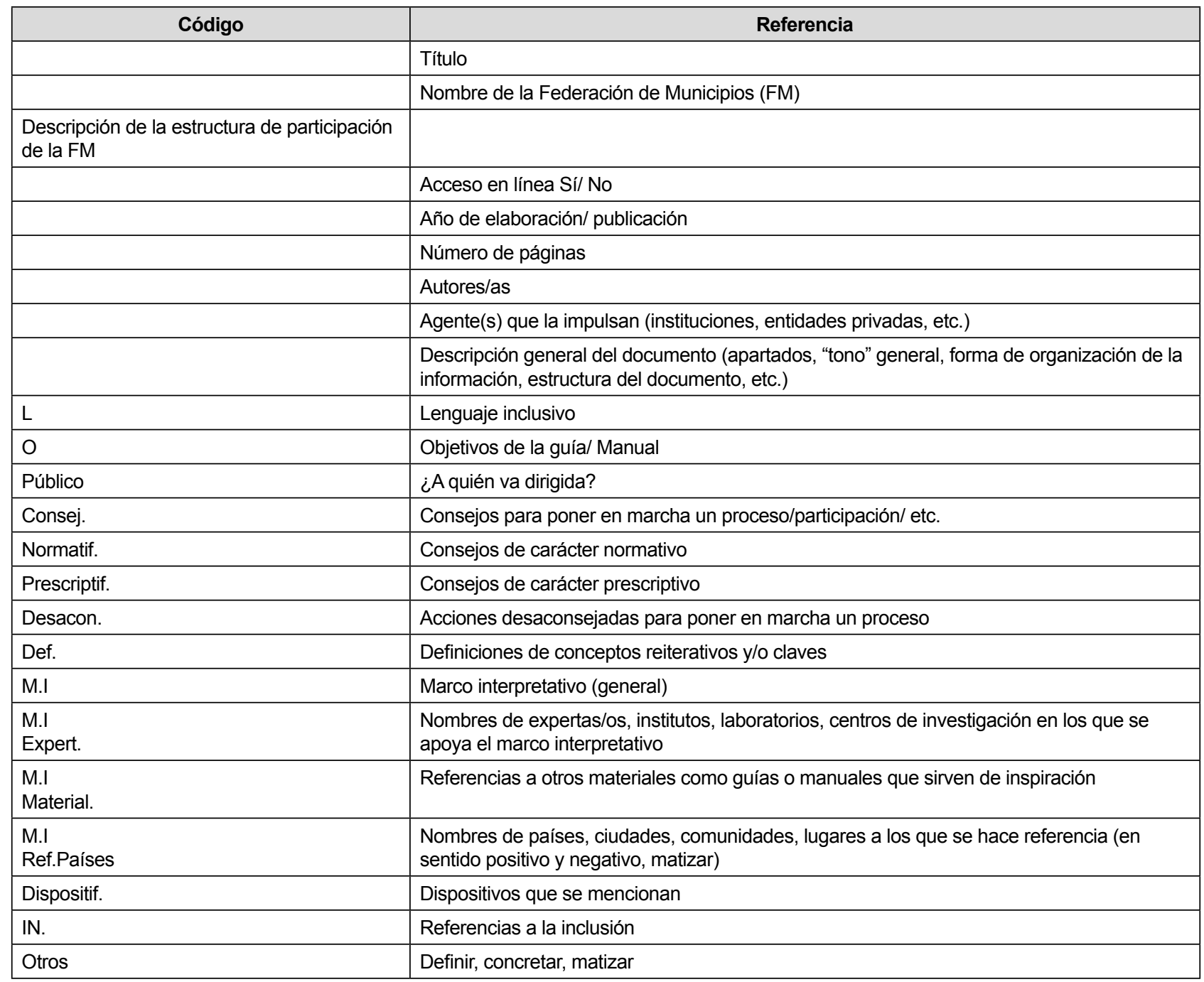

JONE MARTíNEZ-PALACIOS es profesora titular de Ciencia Política y de la Administración de la UPV/EHU. Es miembro del grupo de investigación sobre democracia participativa Parte Hartuz. Entre sus trabajos más recientes en torno de la temática abordada en este artículo se encuentran: El giro participativo neoliberal. UPV/EHU (2021); “¿Qué significa participar? Reflexiones sobre la construcción de las imágenes de la participación”. Papers., vol 103, Núm, 3, 1-27 (2018); "Problemas de la institucionalización y la profesionalización de la participación en contextos de profundización democrática". Revista Internacional de Sociología. 76 (1) (2018); "Contra-públicos feministas e innovaciones democráticas. Estrategias para una profundización democrática inclusiva”. Revista de Estudios Políticos, 178, 105-136 (2017); "Inclusive democratization: normative proposals and political practices". Local Government Studies. 43, 4: 577-597 (2017). 


\section{AGRADECIMIENTOS}

La autora agradece el tiempo dedicado, la energía puesta y el conocimiento aportado por parte de las dos personas revisoras de la primera versión del manuscrito del presente artículo. Asimismo, agradece el trabajo de revisión editorial realizado por el servicio editorial del IESA. 